Article

\title{
The Use of CFD in the Analysis of Wave Loadings Acting on Seawave Slot-Cone Generators
}

\author{
Mariano Buccino ${ }^{1}$, Fabio Dentale ${ }^{2, *}$, Daniela Salerno ${ }^{2}$, Pasquale Contestabile ${ }^{3}$ and \\ Mario Calabrese ${ }^{1}$ \\ 1 Department of Civil, Architectural and Environmental Engineering, University of Napoli FedericoII, \\ via Claudio, 21, 80125 Naples, Italy; buccino@unina.it (M.B.); calabres@unina.it (M.C.) \\ 2 Department of Civil Engineering, University of Salerno, via Giovanni Paolo II, 132, 84084 Fisciano (SA), Italy; \\ dsalerno@unisa.it \\ 3 Department of Civil, Design and Environment Engineering, Università della Campania, Luigi Vanvitelli, \\ via Roma, 29, 81031 Aversa (CE), Italy; pasquale.contestabile@unina2.it \\ * Correspondence: fdentale@unisa.it; Tel.: +39-089-964088
}

Academic Editor: Gregorio Iglesias Rodriguez

Received: 26 September 2016; Accepted: 24 November 2016; Published: 2 December 2016

\begin{abstract}
The reliability of Computational Fluid Dynamics (CFD) in reproducing qualitative and quantitative features of loadings exerted by waves on Seawave Slot-cone Generators (SSG) has been investigated via 17 numerical experiments, conducted with the suite Flow 3D. The geometry of the Wave Energy Converter (WEC), as well as the characteristics of the foreshore in front of it, were identical to those used by the authors in a laboratory study, carried out on a small scale model of a pilot plant to be located along the West Norwegian coasts; the similitude of the layouts allowed an in depth comparison between the results. A good agreement has been generally found between physical and numerical experiments, apart from some aspects of the wave-structure interaction that, however, can be considered secondary for engineering purposes.
\end{abstract}

Keywords: SSG 1; CFD modeling; physical modeling; wave forces; wave pressures

\section{Introduction}

In 2015, renewable energy set new records for dollar investment and amount of new capacity added, in spite of the plummeting of the fossil fuel price [1]. The reasons of this surprising result include of course the climate change policies, which encourage the de-carbonization of the energy sector, and the improved cost-competitiveness of new technologies.

Wave energy has the potential to be a particularly valuable contributor to a low-carbon energy mix since, besides being very abundant [2-4], it has a different geographic distribution than wind and solar, greater predictability and less intermittency. Accordingly, even in the awareness that only a small fraction of this huge resource can be exploited (see also [5]), more than 1000 Wave Energy Converters (WECs) have been patented worldwide.

WECs can be generally divided into three categories, based on the working principle. In the Oscillating Water Column (OWC) technology, a cushion of air is trapped within a partly submerged chamber where the water level rises and falls with the waves. The oscillating motion makes the air to pass through a turbine, which rotates in the same direction irrespective of the way of flow. Wave Activated Bodies (WAB) exploit the relative motion of the different parts of the device; hydraulic systems are generally employed to compress oil, air or water, which are then used to drive a generator [6,7]. In the Over Topping Devices (OTD), a sloping plate leads the waves to overtop into a reservoir. The energy is then extracted via a turbine that works with small head differences (below $3 \mathrm{~m}$ ) and large flow volumes. 
Despite most of the research efforts are addressed at solving the problem of the low efficiencies of the plants, an additional serious hurdle to the WECs development and diffusion is undoubtedly represented by the uncertainties related to their capability of resisting wave actions [8-10].

Due to the notable complexity of the hydrodynamic processes involved in the wave-device interaction (wave breaking, wave reflection/diffraction, wave overtopping, etc.), the structural design of wave energy converters invariably requires lengthy and expensive physical model studies, whose impact on the total cost of plants may be not negligible.

In this respect, the use of Computational Fluid Dynamics (CFD), which solves the Navier-Stokes Equations coupled with a turbulence model, could represent a valuable alternative, either as a surrogate of physical modeling [11] or as a support to reduce the number of tests and measurements required.

However, for the specific case of the structural response of WECs, there is a lack of rigorous validation studies that compare outcomes of lab experiments to those of CFD simulations. Of course this limits the use of the latter in the current design practice.

This article aims at partially filling this gap, dealing with the case of the Seawave Slot-Cone Generator (SSG, Figure 1).

Patented by WavEnergy SAS (Stavanger, Norway), this OTD includes a number of reservoirs placed on the top of each-other, which capture the water during the up-rush phase; on its way back to the sea, the fluid passes through a low-head turbine, spinning it and producing electricity [12-14].

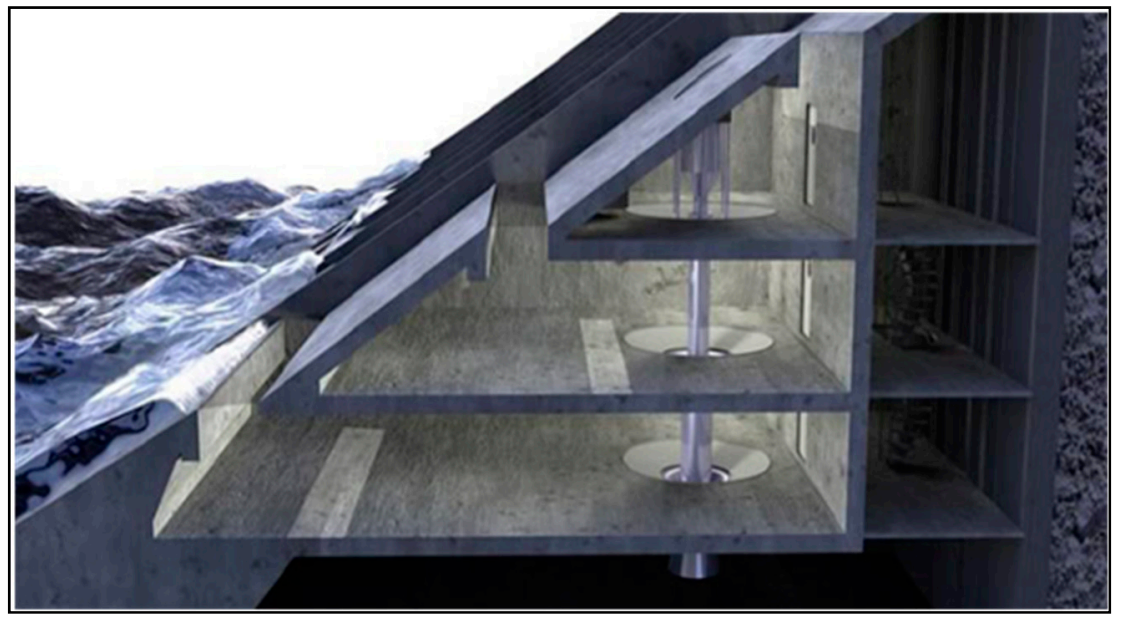

Figure 1. Artistic representation of a three-level Seawave Slot-Cone Generator (SSG); modified with permission from Buccino et al. [15].

The WEC is normally located at the top of a steep foreshore, which will be nicknamed "focuser" in the following, as it has the main purpose of increasing the potential run-up height.

In 2015, Buccino et al. [15] carried out a number of regular wave experiments at the LinC laboratory of the Department of Civil, Architectural and Environmental Engineering of the University of Naples "Federico II", on a small scale model of SSG originally designed as a possible pilot plant to be located at Svåheia, along the West Norwegian coasts. The authors provided a detailed description of the nature of loadings acting onto the front face of the WEC and produced a parameterization of the obtained results.

The research above represents, then, a good reference for a detailed comparison with numerical simulations.

This article is organized as follows. Section 2 provides a brief review of the existing literature on the structural response of SSGs and summarizes the main results of Buccino et al. [15]. In Section 3, the numerical CFD experiments are described and Section 4 discusses the results of comparison with the physical model tests. In Section 5, conclusions are finally drawn. 


\section{Literature}

In 2009, Vicinanza and Frigaard [16] carried out a physical model study to investigate the structural response of a 1:60 model of Seawave Slot-cone Generator. Since the focuser was extremely steep (1:1), the authors observed essentially non-breaking waves and quasi-static loadings. It was found out that the predictive method proposed by Takahashi et al. [17] for sloping top caisson breakwaters, could not be extended to the case of SSGs, since the peaks of horizontal force were dramatically under-predicted.

Successively, Vicinanza et al. and Buccino et al. [14,18] showed that non-impulsive wave actions induced by both non-breaking and breaking waves, could be estimated, up to a certain extent, by the Japanese design formulas for trapezoidal monolithic barriers [19].

More recently, Buccino et al. [15] have suggested a calculation method, expressly derived for SSGs, which holds for both impulsive and non-impulsive loadings. The method is essentially probabilistic and is based on a series of regular wave laboratory experiments, conducted by the authors on a model of WEC scaled down at 1:66.

The approach employs three predictive variables and namely:

(1) The surf similarity parameter or inshore Iribarren number $(\xi)$ [20] calculated with the incident wave height at the toe of the focuser, $H_{i}$, the wave period $T$ and the average front slope angle, $\operatorname{tg} \alpha_{a v}$. (Figure 2);

$$
\xi=\frac{\operatorname{tg} \alpha_{a v}}{\sqrt{\frac{2 \pi H_{i}}{g T^{2}}}}
$$

(2) The (mean) slope parameter [21], i.e., the ratio between the length of the waves at the toe of the focuser ( $L$ at the depth $d$, Figure 2 ) and the mean horizontal distance between the toe of the foreshore and the shoreline $\left(d / \tan \alpha_{a v}\right.$.):

$$
S=\frac{\operatorname{L\cdot tg} \alpha_{a v}}{2 \pi d}
$$

(3) The Linear Thrust Parameter, which represents the ratio between the maximum value (over a wave period) of the wave momentum flux through the base of the focuser and the corresponding hydrostatic still water thrust:

$$
L_{T P}=\frac{H_{i}}{d} \frac{\tanh (k d)}{k d}
$$

$L_{T P}$ is in fact a linearized-slightly-modified form of the wave Momentum Flux Parameter $\left(M_{F P}\right)$ originally introduced by Hughes [22] (see also [23]); in shallow waters it reduces to the wave height to depth ratio $H_{i} / d$.

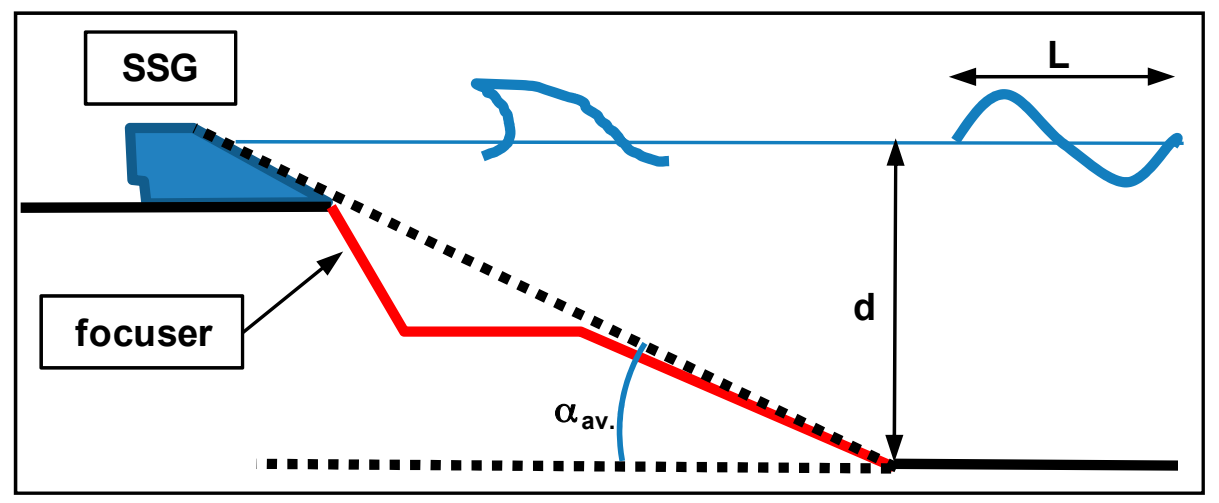

Figure 2. Definition of average front slope $\operatorname{tg} \alpha_{a v}$. The angle is taken from the toe of the focuser to the top of the SSG. 
Only two of the three variables above are independent, since it can be proven that:

$$
\sqrt{\frac{L_{T P}}{2 \pi}} \xi=S
$$

Buccino et al. found out that the wave shapes at the wall could be efficiently distinguished using a chart where $\xi$ is on the abscissas and $L_{T P}$ is on the ordinates (Figure 3); on this plane, all the variables relevant to the breaking process (slope angle, wave steepness, and wave height to depth ratio [24]) are in fact expressly taken into account.

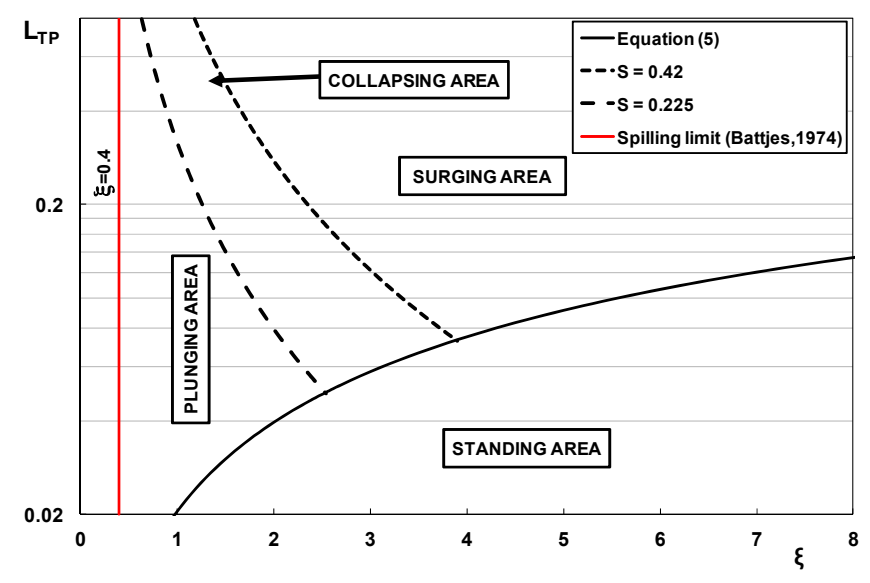

Figure 3. The plane $\xi$ and $L_{T P}$, modified with permission from Buccino et al. [15]. The graph includes the limit for spilling breakers $(\xi=0.4)$, as suggested by Battjes (1974).

The Figure 3 shows that for any value of the Iribarren number, wave breaking takes place only if the momentum flux at the toe of the focuser exceeds a threshold (black solid line), which increases with growing $\xi$. The equation of the limit curve is:

$$
L_{T P}=\frac{0.021 \xi}{1+0.031 \xi}
$$

in which $L_{T P}$ tends to 0 for small values of the Iribarren number, as on very mild slopes the waves are always expected to break.

The different breaker types can be then discriminated based on the value of $S$; the analysis of the experimental data suggested to choose $S=0.420$ and $S=0.225$ as preliminary limits for the transitions from surging to collapsing and from collapsing to plunging.

As far as wave forces are concerned, the classification introduced for vertical breakwaters within the EU funded project PROVERBS has been adopted [25]. Accordingly, a force chronogram is termed "pulsating" if it exhibits a unique smooth peak over a wave period (Figure 4, left panel); a double peak pattern is instead named either "slightly breaking" or "impact" (see also [26,27]), depending on whether the first sharp maximum $\left(F_{h, \max }\right.$ in Figure 4$)$ is lower or higher than 2.5 times the second "pulsating" peak $\left(F_{h, q}\right)$.

For prediction purposes, Buccino et al. [15] reasoned that due to the inherent randomness of the breaking process, even under a "regular wave" attack the structural response could be best represented by a probability density function ( $p d f$ ) of wave pressure, rather than a single deterministic value. Thus, it was assumed that for any $H_{i}$ and $T$, the average hydrodynamic pressure acting onto the front face of the WEC at the instant of maximum force ( $\hat{p}_{a v}$. in Figure 5) could be approximately described via a $\log$-normal $p d f$. 


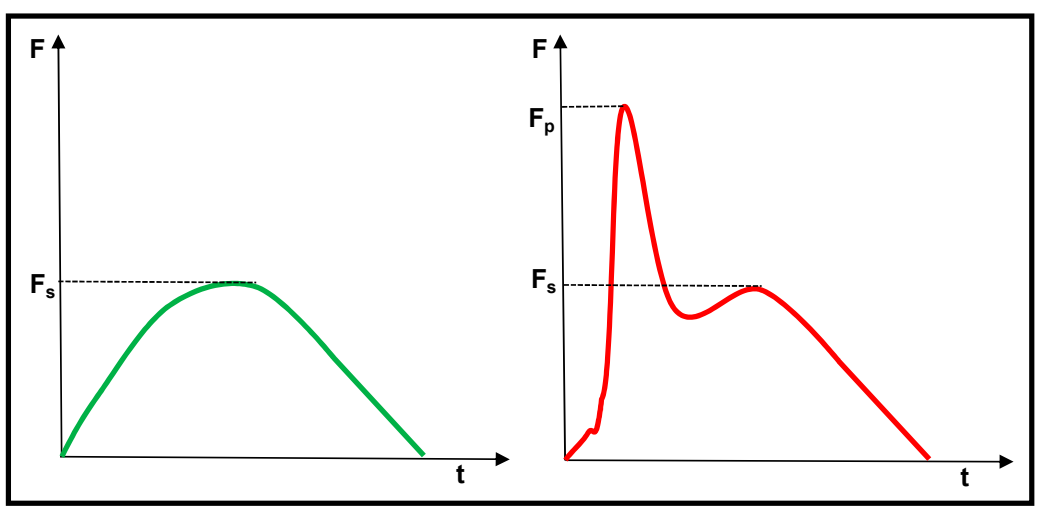

Figure 4. Examples of horizontal force time history at the front face of SSG. Left panel: pulsating event; right panel: breaking event.

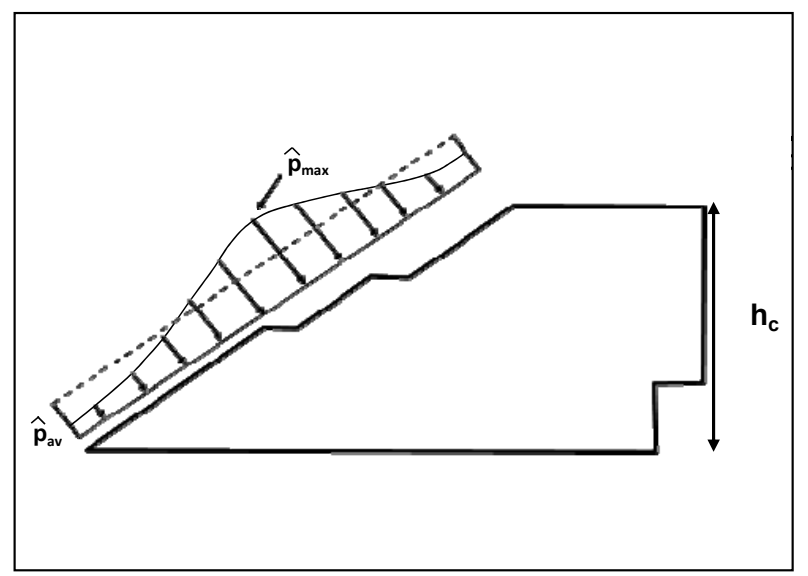

Figure 5. Definition of instant of maximum force $\left(p_{a v}\right)$. Modified with permission from Buccino et al. [15].

Mean and standard deviation of the distribution can be calculated employing different equations, based on whether the nature of loadings is expected to be impulsive (i.e., induced by plunging breakers) or not. The authors proposed:

$$
\begin{gathered}
E\left(\frac{\hat{p}_{a v .}}{\rho g d}\right)=\left\{\begin{array}{c}
0.751 L_{T P} \text { non impact waves } \\
{\left[2.68 \xi^{-2.42}\right] L_{T P} \text { impact waves }}
\end{array}\right. \\
\sqrt{\operatorname{VAR}\left(\frac{\hat{p}_{a v .}}{\rho g d}\right)}=\left\{\begin{array}{c}
0.0012+0.0474 u+0.8017 u^{2} \text { non impact waves } \\
0.0009 \exp (10.39 t) \text { impact waves }
\end{array}\right.
\end{gathered}
$$

where

$$
\left\{\begin{array}{l}
u=\frac{L_{T P}}{\xi^{0.6}} \\
t=\frac{L_{T P}^{0.3}}{\xi}
\end{array}\right.
$$

Equation (6) should be applied within the ranges:

$$
\left\{\begin{array}{c}
0.03 \leq L_{T P} \leq 0.32 \\
0.015 \leq \xi^{-2.42} L_{T P} \leq 0.108
\end{array}\right.
$$


whereas the limits of Equation (7) are:

$$
\left\{\begin{array}{l}
0.0157 \leq u \leq 0.2600 \\
0.2407 \leq t \leq 0.4933
\end{array}\right.
$$

By means of the Equations (6) and (7), the structural design of the WEC can be then performed calculating wave loadings as a function of the probability of failure the designer considers the most appropriate to the specific project.

\section{Numerical Experiments}

Numerical experiments have been conducted via the suite Flow 3D (Flow Science, Santa Fe, Mexico) [28], which has been proven to be particularly accurate in solving wave-structure interaction problems $[29,30]$. The software solves the Reynolds Averaged Navier-Stokes Equations (RANS) combined with a Volume of Fluid (VOF) method. For the present application, a Re-Nornalization Group (RNG) $k$-epsilon turbulence closure has been chosen.

The SSG and the focuser reproduce the Svåheia project at a full scale (Figure 6) and are geometrically identical to those employed in Buccino et al. [15] (apart from the obvious scaling up). Like in the physical model tests, the sea bottom has been kept constant seaward the focuser (Figure 6b); the distance between the latter and the wave-maker has been fixed at $277 \mathrm{~m}$.

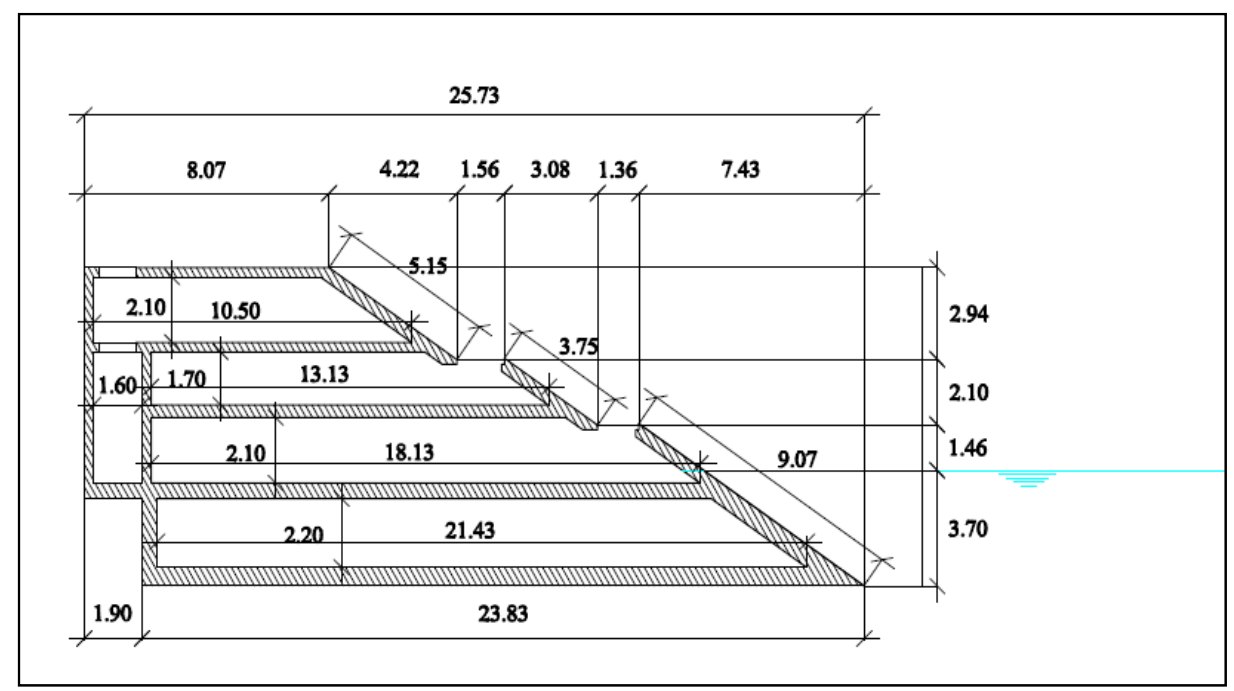

(a)

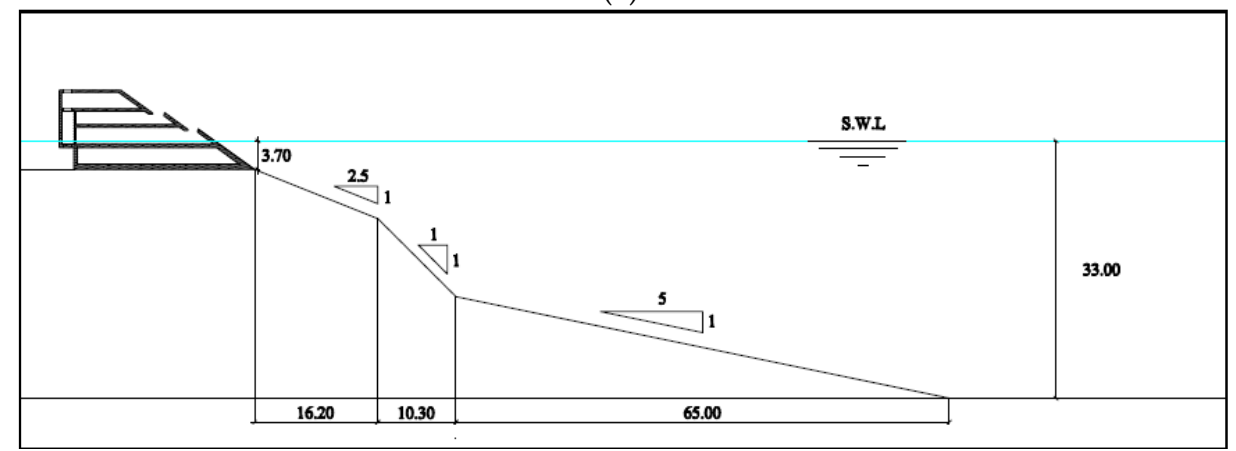

(b)

Figure 6. (a) Section of the prototype of the SSG; and (b) the foreshore with the location of the SSG at a full scale. S.W.L. stands for Still Water Level Dimensions in $\mathrm{m}$. 
The use of a full scale CFD model allows minimizing the numerical viscosity effects induced by the turbulence closure, which may lead to significantly dampen waves and loadings on a small scale structure. On the other hand, though, the use of different scales between physical and numerical experiments could introduce some uncertainties in the comparison of results. However, since the models here analyzed are both smooth and impermeable (the SSG reservoirs have been supposed to be closed during the wave attacks), no relevant scale effects due to the dynamic viscosity of the fluid are expected to occur [31]. The main bias is rather related to the absence of air in the CFD, the consequences of which are discussed in the Section 4 .

\subsection{Grid Selection}

The computational domain (400 $\mathrm{m}$ in the $X$ direction and $60 \mathrm{~m}$ in the $Z$ direction, Figure 7 ) is made up on three zones (Figure 8a): meshes 1 and 3 include 62,400 and 14,400 cells of size $50 \mathrm{~cm} \times 50 \mathrm{~cm}$, respectively. The size of the local mesh that surrounds the WEC (mesh 2, Figure 8b), has been instead selected based on an ad hoc sensitivity analysis.

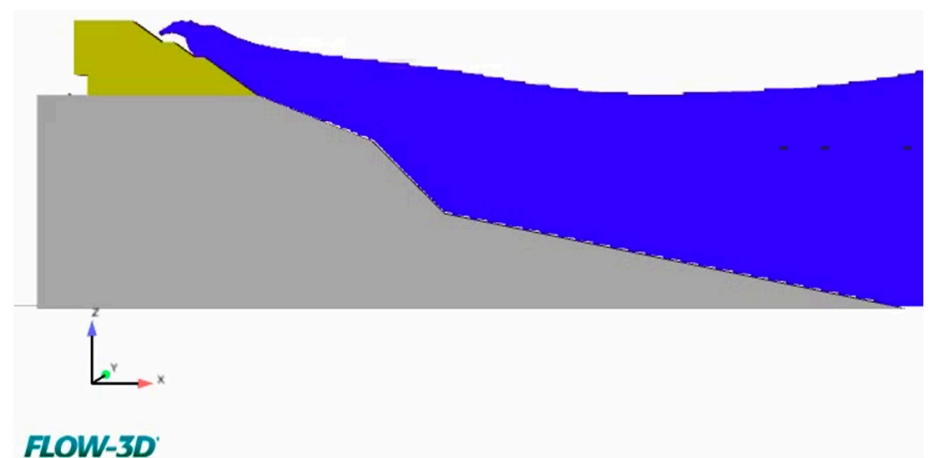

Figure 7. The model of the SSG and the bathymetry in Flow 3D.

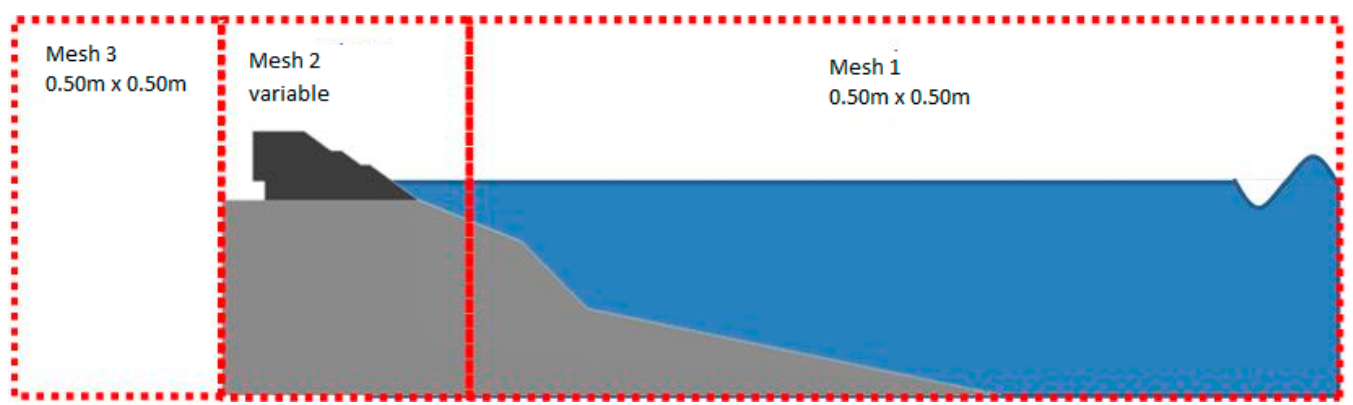

(a)

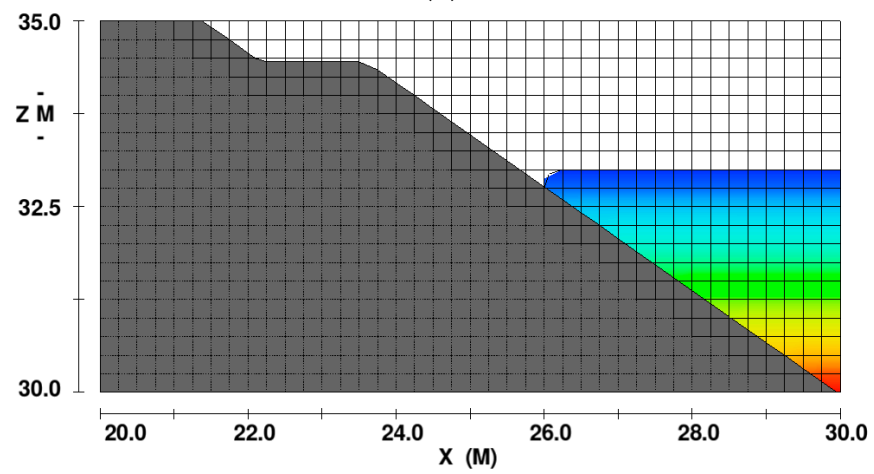

(b)

Figure 8. (a) View of the computational domain; and (b) detail of mesh 2. 
In this view, three grids have been initially compared, that measured respectively $50 \mathrm{~cm} \times 50 \mathrm{~cm}$, $25 \mathrm{~cm} \times 25 \mathrm{~cm}$ and $8 \mathrm{~cm} \times 8 \mathrm{~cm}$. Each grid has been subjected to the same regular wave attack $(H=3.78 \mathrm{~m}, T=8.02 \mathrm{~s})$ and the time history of the horizontal force exerted on the SSG has been analyzed.

The waves are generated by imposing a periodic fluctuation of the water level at the seaward end of the flume; the corresponding velocity is then calculated via the linear wave theory. It is worth noting that for each mesh size, an optimal time interval is internally selected by the software to avoid any numerical instability.

The Figure 9 shows an example of the obtained results.
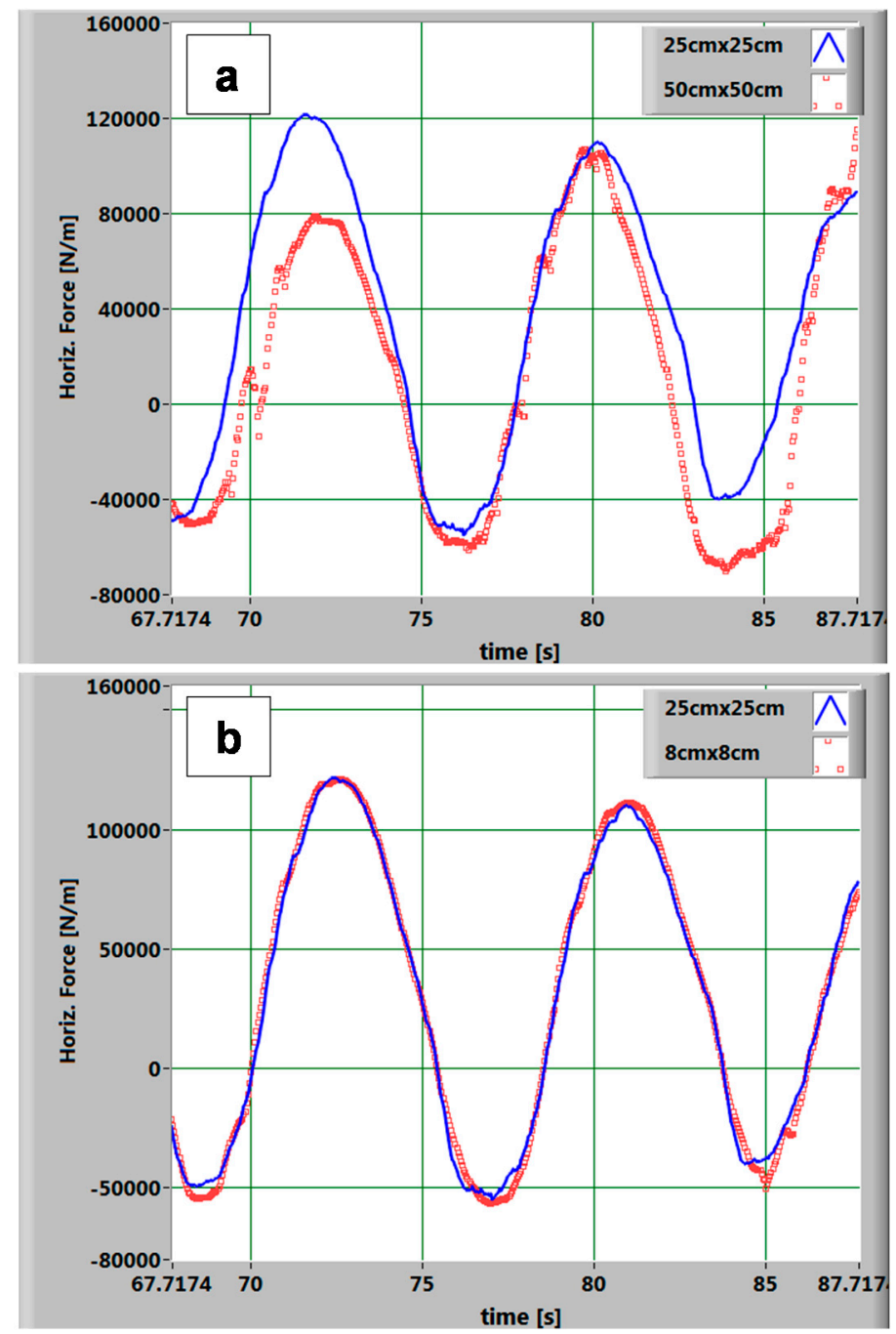

Figure 9. Horizontal force signal at the wall for different grid sizes. (Panel a) $25 \mathrm{~cm} \times 25 \mathrm{~cm}$; (Panel b) $25 \mathrm{~cm} \times 25 \mathrm{~cm}$ vs. $8 \mathrm{~cm} \times 8 \mathrm{~cm}$.

The force signal associated to the grid $50 \mathrm{~cm} \times 50 \mathrm{~cm}$ deviates significantly from that of the grid $25 \mathrm{~cm} \times 25 \mathrm{~cm}$ (Figure 9a); conversely, the latter appears almost identical to the time history associated with $8 \mathrm{~cm} \times 8 \mathrm{~cm}$ (Figure 9b), indicating that a convergence in the results has been achieved. This can also be quantitatively observed through the indexes reported in Table 1 . Here the coefficient of determination between the signals, $R^{2}$, and the relative Root Mean Square Error (RMSE) of the coarser grid results compared to finer grid ones are calculated. 
Table 1. Root Mean Square Error (RMSE) and index of determination $\left(R^{2}\right)$ for different grid size.

\begin{tabular}{ccc}
\hline GRID & RMSE & $\boldsymbol{R}^{\mathbf{2}}$ \\
\hline $50 \times 50$ vs. $25 \times 25$ & 6.36 & 0.86 \\
$25 \times 25$ vs. $8 \times 8$ & 0.37 & 0.99 \\
\hline
\end{tabular}

It is seen that, passing from $25 \mathrm{~cm} \times 25 \mathrm{~cm}$ to $50 \mathrm{~cm} \times 50 \mathrm{~cm}$, a relative error exceeding $600 \%$ is produced, whereas the correlation between the signals is only moderately high. On the other hand, between $25 \mathrm{~cm} \times 25 \mathrm{~cm}$ and $8 \mathrm{~cm} \times 8 \mathrm{~cm}$, the RMSE reduces dramatically and the value of $R^{2}$ indicates an almost perfect coherence between the results. Thus, a $25 \mathrm{~cm} \times 25 \mathrm{~cm}$ mesh size has been finally selected for this study.

\subsection{Test Program}

Consistently with Buccino et al. [15], regular wave experiments have been run with the same still water level as used in the physical lab $(d=33 \mathrm{~m})$. Table 2 reports the values of the incident wave parameters $H_{i}$ and $T$ (see Section 4 ), along with the sampling rates $\left(\Delta t^{*}\right)$ employed for both wave and loading signals.

Table 2. Wave characteristics (prototype scale) for CFD experiments.

\begin{tabular}{cccc}
\hline TEST\# & $\boldsymbol{H}_{\boldsymbol{i}}[\mathrm{m}]$ & $\boldsymbol{T}[\mathrm{s}]$ & $\boldsymbol{\Delta} \boldsymbol{t}^{*}[\mathrm{~s}]$ \\
\hline 1 & 3.01 & 6.70 & 0.03 \\
2 & 3.73 & 6.64 & 0.03 \\
3 & 4.34 & 6.65 & 0.03 \\
4 & 4.68 & 6.63 & 0.03 \\
5 & 4.75 & 6.63 & 0.03 \\
6 & 2.61 & 8.01 & 0.04 \\
7 & 3.78 & 8.02 & 0.04 \\
8 & 4.58 & 8.04 & 0.04 \\
9 & 5.25 & 8.03 & 0.04 \\
10 & 6.08 & 8.03 & 0.04 \\
11 & 6.95 & 8.01 & 0.04 \\
12 & 7.71 & 8.00 & 0.04 \\
13 & 8.29 & 7.99 & 0.04 \\
14 & 1.25 & 17.15 & 0.08 \\
15 & 2.32 & 17.05 & 0.08 \\
16 & 6.50 & 17.03 & 0.08 \\
17 & 11.55 & 16.40 & 0.08 \\
\hline
\end{tabular}

Notes: Incident wave height $\left(H_{i}\right)$, wave period $(T)$ and sample rate $\left(\Delta t^{*}\right)$.

It is worth noticing that in all the tests there was no water at the rear of the WEC, apart that coming from the wave overtopping.

\subsection{Data}

A video of each experiment has been taken, to study the wave shape at the wall and the fundamentals of the wave-structure interaction. The fluctuations of the free surface were acquired at each cell seawards the focuser. Finally, the horizontal component of the total force acting on the front face of the SSG has been extracted, along with four pressure time series from transducers placed in the same positions as in Buccino et al. [15] (Figure 10 and Table 3). 


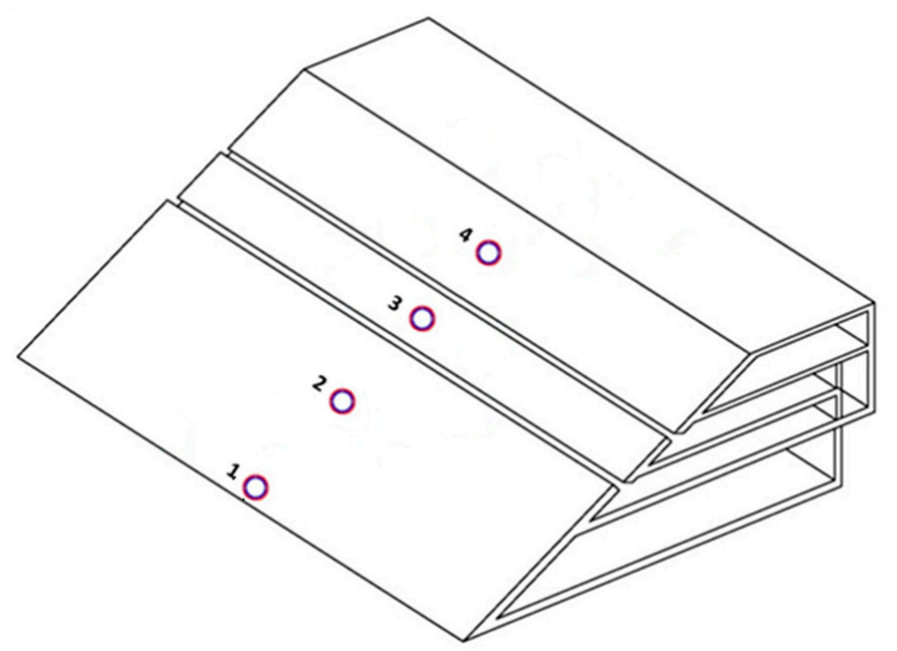

Figure 10. Location of the transducers along the outer face of the SSG. Modified with permission from Buccino et al. [15].

Table 3. The position of the sensors from the toe of the structure.

\begin{tabular}{cc}
\hline Transducer\# & Transducer Centre from the SSG Toe [m] \\
\hline 1 & 0.93 \\
2 & 3.70 \\
3 & 6.24 \\
4 & 8.75 \\
\hline
\end{tabular}

\section{Comparison between Results of Numerical and Physical Model Tests}

\subsection{The Reflection Coefficient}

Like for the physical model tests, in this study, the reflection coefficient $k_{r}$ (reflected to incident wave height ratio) has been measured on the flat bottom seaward the focuser; thus, unlike Zanuttigh et al. [32], it gathers the effects of both the WEC and the foreshore.

The reason for using this variable as starting point of our analysis, is that it can be considered as a global indicator of the wave-structure interaction characteristics; this in virtue of its dependence on wave run-up, wave overtopping and dissipation rate.

Incident and reflected signals have been separated via the method of Zelt and Skjelbreia [33], following the same procedure described by Buccino et al. [15]. To this aim, the signals of four wave probes have been simultaneously analyzed.

In Figure 11, numerical $k_{r}$ s and data of Buccino et al. [15] are plotted vs. the Iribarren number and the relative crest freeboard $R_{c} / H_{i}$. As widely known, the former variable controls the breaking process, whereas the latter is strongly correlated to the average overtopping discharge. The two graphs show that an increase of reflection occurs both when the rate of energy dissipated by breaking decreases (large $\xi$ ) and when the amount of overtopping reduces (high values of $R_{c} / H_{i}$ ).

Physical and numerical data are seen to lie within the same cloud, indicating a good consistency. However, for a given $R_{c} / H_{i}$, CFD gives less reflection, which is likely due to a larger amount of overtopping. 


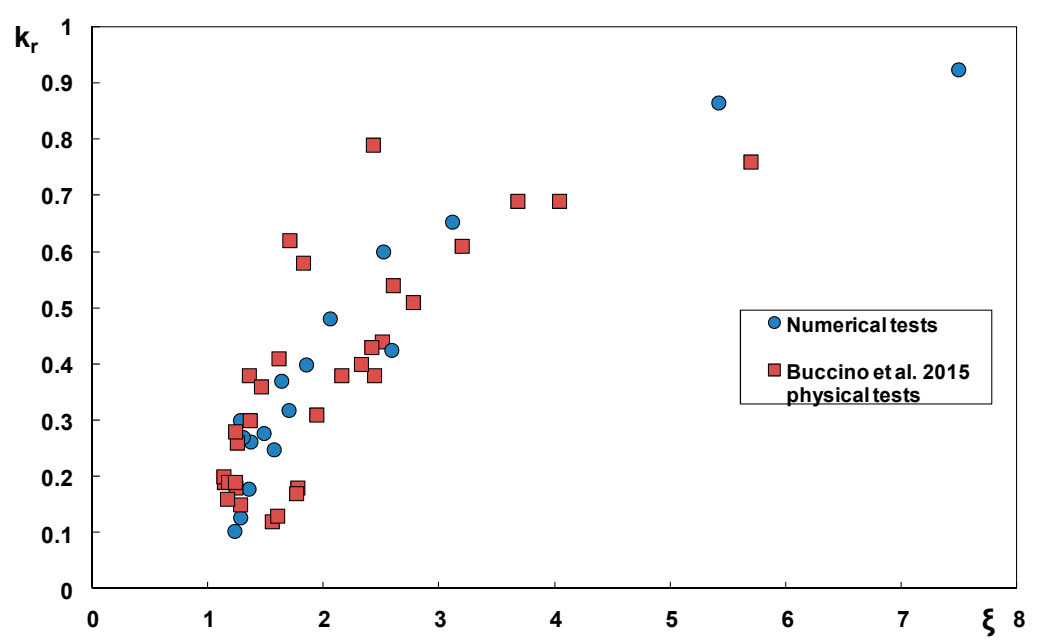

(a)

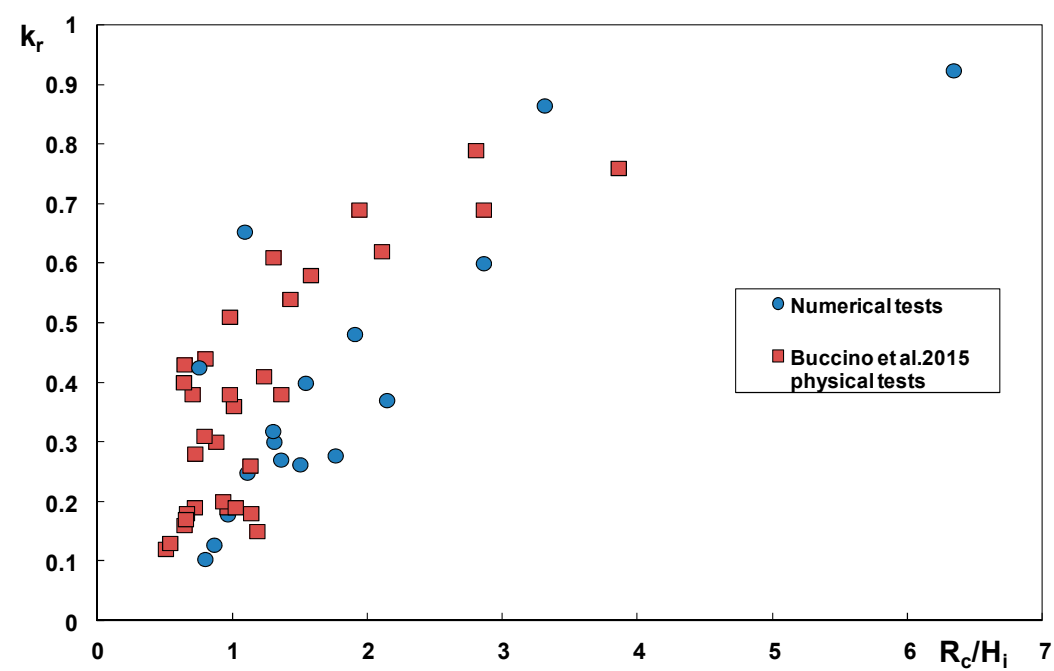

(b)

Figure 11. (a) The reflection coefficient $\left(k_{r}\right)$ as a function of the Iribarren number ( $\xi$ ); and (b) the reflection coefficient as a function of the relative crest freeboard $\left(R_{c} / H_{i}\right)$.

\subsection{Wave Shapes at the Wall}

From the inspection of videos, the shape of the wave profile at the system "wall + focuser" was identified for each experiment. Like in Buccino et al. [15], the classification adopted follows the approaches described in Basco [34] and Calabrese et al. [24]. The results of the analysis are pictured in Figure 12, on the plane $\xi-L_{T P}$. Overall, the numerical simulations appear in agreement with the outcomes of the physical model tests; the majority of data refers to plunging breakers, which fall consistently within the area with $S \leq 0.225$. Only in two cases, a mismatch has been observed; one refers to a plunging breaker within the "standing area", the other is a standing wave observed in the plunging zone. Both the points, however, are quite close to the curve of incipient breaking, so that the observed discrepancy is likely ascribable to the inherent randomness which affects the breaking process even under regular waves [35]. It should be also added that in the present case the stability of waves is strongly influenced by the rate of reflection and accordingly small variations of $k_{r}$ may produce different profiles at the wall. 


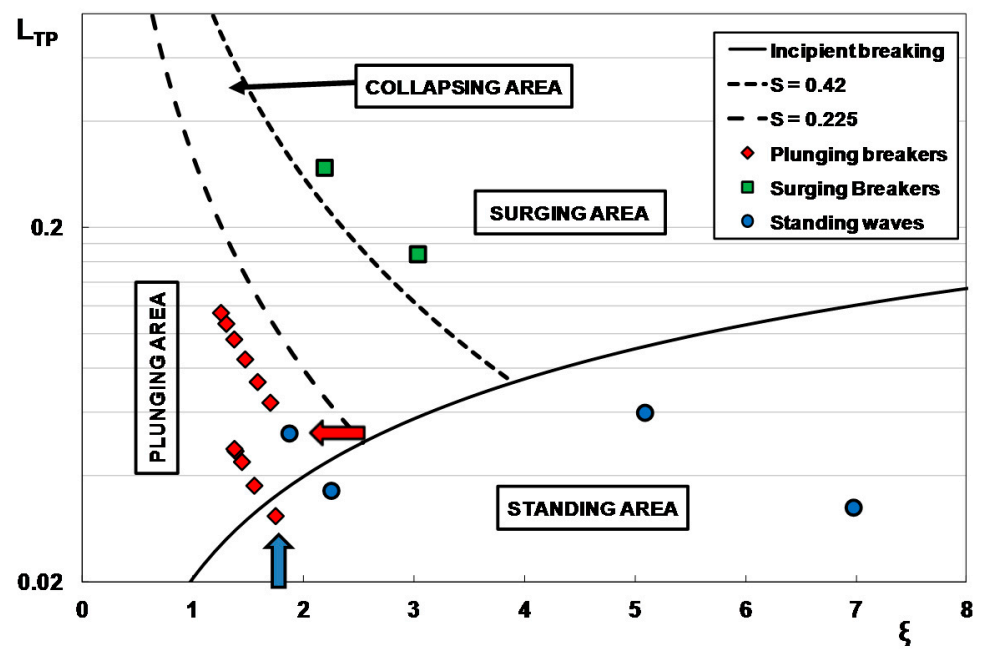

Figure 12. Breaker types observed at the SSG.

\subsection{Direct Comparison of Pressure and Force Signals}

The numerical tests 6, 12 and 17 in Table 2 have wave height and period rather similar to those of three experiments presented in the study of Buccino et al. [15]. As shown in Table 4, the wave shapes observed at the wall are the same, the scatter on $H_{i}$ does not exceed $10 \%$ and the difference on $T$ is not larger than $2 \%$. This degree of similitude allows, then, a direct comparison in terms of pressure and force chronograms.

Table 4. Relative percentage error (ERR) between wave characteristics (incident wave height $H_{i}$ and period $T$ ) in numerical (CFD) and physical tests.

\begin{tabular}{ccccccccc}
\hline \multirow{2}{*}{ TEST\# } & \multicolumn{2}{c}{ CFD } & \multicolumn{2}{c}{ PHYSICAL } & \multicolumn{2}{c}{ ERR (\%) } & \multicolumn{2}{c}{ BREAKER TYPE } \\
\cline { 2 - 8 } & $\boldsymbol{H}_{\boldsymbol{i}}[\mathrm{m}]$ & $\boldsymbol{T}[\mathrm{s}]$ & $\boldsymbol{H}_{\boldsymbol{i}}[\mathrm{m}]$ & $\boldsymbol{T}[\mathbf{s}]$ & $\boldsymbol{H}_{\boldsymbol{i}}$ & $\boldsymbol{T}$ & Physical & Numerical \\
\hline A & 2.61 & 8.01 & 2.37 & 8.12 & 10 & 1 & Standing & Standing \\
B & 7.71 & 8.00 & 7.62 & 8.12 & 1 & 2 & Plunging & Plunging \\
C & 11.55 & 16.40 & 10.70 & 16.33 & 8 & 0 & Surging & Surging \\
\hline
\end{tabular}

The Figure 13 refers to the test 6 , where the waves are simply reflected by the SSG. In this graph, like in the similar ones reported in the following, the loading signals are kept voluntarily out of phase to facilitate the comparison.

Although shape and magnitude of pressure signals appear consistent on average, CFD is observed to generate low impulse spikes and a slightly lower level of run-down (trough of the pressure waves in the panel $\mathrm{p}_{1}$ ). It is also of interest that the pressure at the transducer $\mathrm{p}_{4}$ is zero both in the numerical and the physical test.

The presence of spikes in the numerical pressures, which resulted almost independent of the grid size, is likely related to the features of the up-rush process. As shown in Figure 14, while climbing the WEC the run-up wedge has been observed to steepen and project a small tongue of fluid against the wall, whose impact is probably responsible of the appearance of the secondary peaks. This phenomenon, which occurs repeatedly during the up-rush phase, is likely created by the segmented shape of the SSG. 

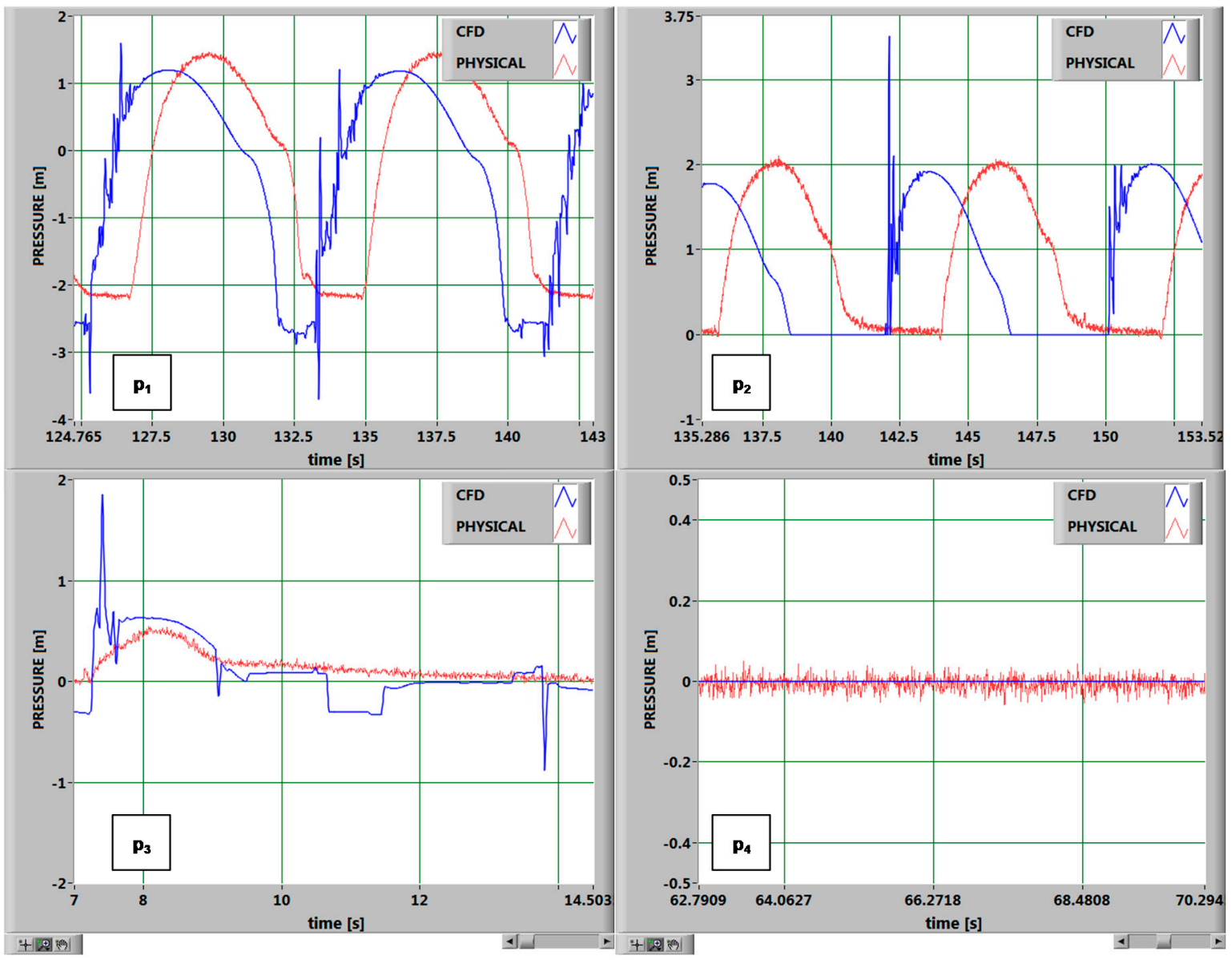

Figure 13. Numerical vs. Physical Pressure chronograms (Test 6). Pressures are expressed in water column. $\mathrm{p}_{1}$ : pressure transducer at the toe of the structure; $\mathrm{p}_{2}$ at the still water level; $\mathrm{p}_{3}$ and $\mathrm{p}_{4}$ on the upper plates (see Figure 10).

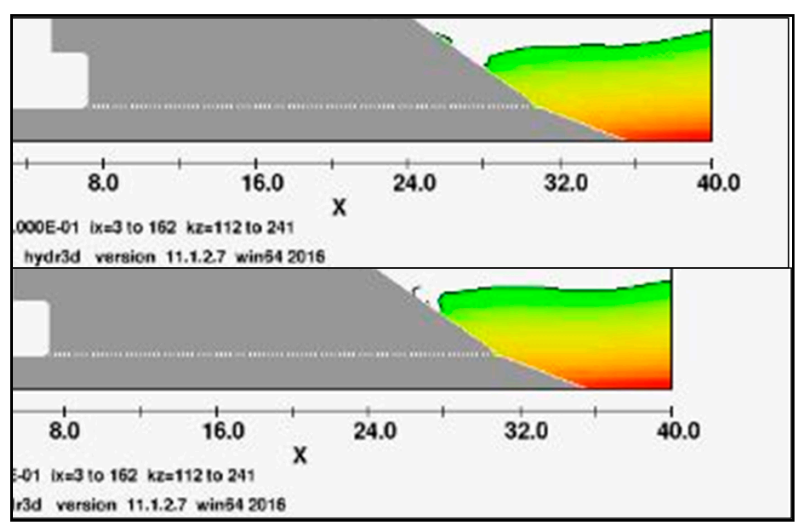

Figure 14. Details of the up-rush phase for test 6.

The spikes make the CFD chronogram of the horizontal force more noisy compared to that of the physical experiment; moreover, a weak increase of phase difference has been observed in the last part of the signal, as shown in the upper panels of the Figure 15. On the other side, the two chronograms appear rather consistent in magnitude and the distribution of pressures in $\mathrm{p}_{1}-\mathrm{p}_{4}$, and, at the instant of the maximum force, has been found to be bi-trapezoidal in both cases (Figure 15, lower panels). 


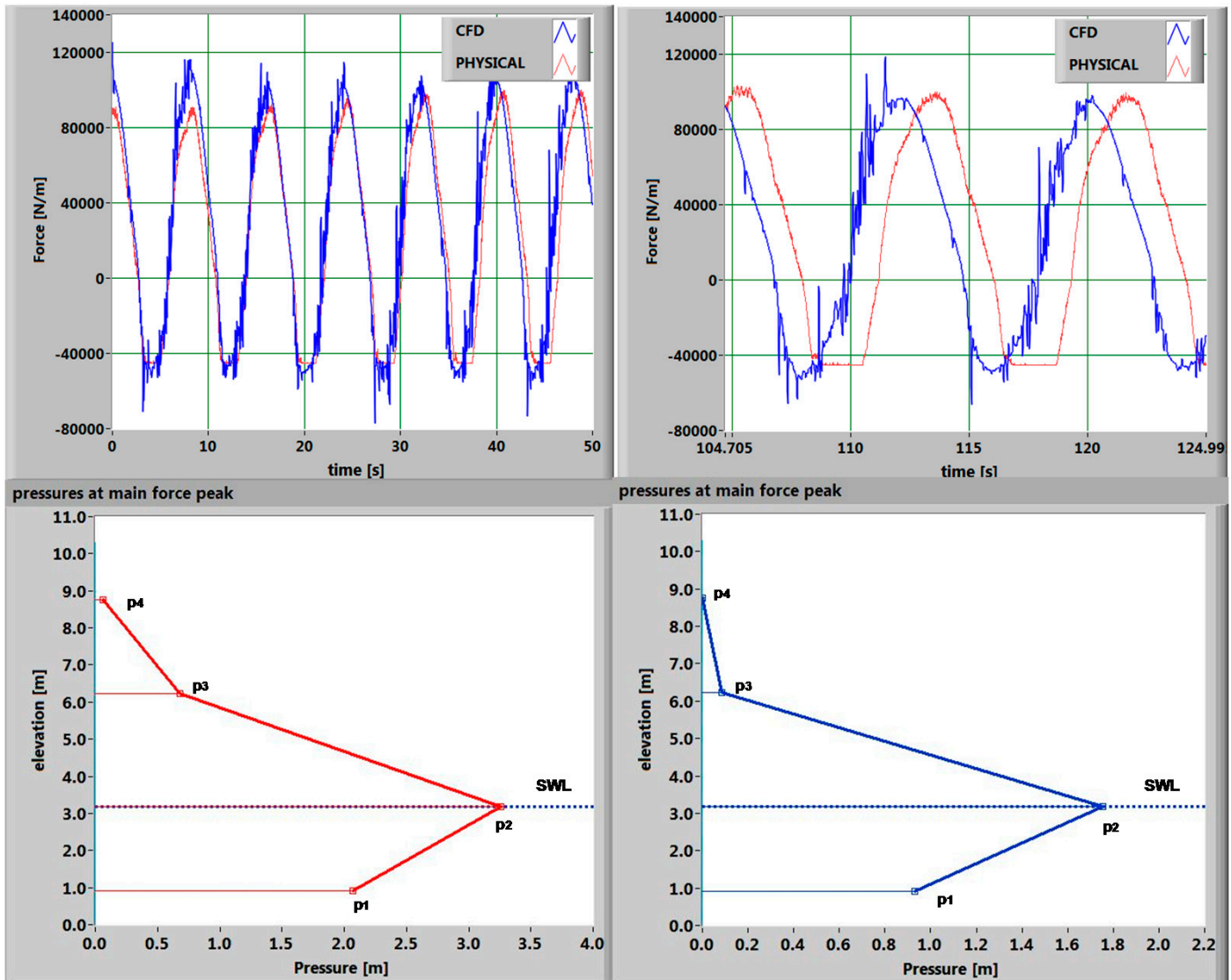

Figure 15. Upper panels: numerical vs. physical chronograms of horizontal force (Test 6). Lower panels: distribution of pressures at the instant of maximum force (the blue solid line is CFD).

Test 12 refers to a plunging breaker and the observed wave kinematics is generally consistent with that described in several studies conducted on vertical face breakwaters [26,27]. Both in the physical and the CFD experiments, the plunging jet $[24,34]$ is observed to strike the lower part of the WEC (upper panels in Figure 16), with the mass of water that splashes-up and hits again the wall onto the higher plate (lower panels in Figure 16). These two impacts are clearly visible in the time history of the horizontal force (Figure 17a); it is also noteworthy that at the main peak (maximum force), the distribution of pressures results triangular with the maximum in $\mathrm{p}_{1}$ (Figure 17b).

As mentioned earlier, the main difference in this case concerns the effect of air, not modeled in the CFD, which produces a series of oscillations of a nearly $10 \mathrm{~Hz}$ frequency (in prototype) both in the force and the pressure signals of the physical model test. Generally, however, the agreement between the pressure chronograms is rather satisfactory (Figure 18).

Test 17 is a large surging breaker; Buccino et al. [15] argued that under such condition, pulsating-type chronograms alternate with slightly breaking time-histories. The latter are generated by a water jet detaching from the wave profile during the up-rush phase. These features have been qualitatively observed in the CFD experiment also, but pulsating events appear less "linear", with a rise-time significantly shorter (Figure 19a,b). Moreover, impact time-histories have been detected instead of the slightly breaking ones (Figure 20a,b); this is likely due to the fact that in the physical experiment, a large area of spray forms during the up-rush, which dampens the slam of the water tongue onto the upper plates of the WEC. 


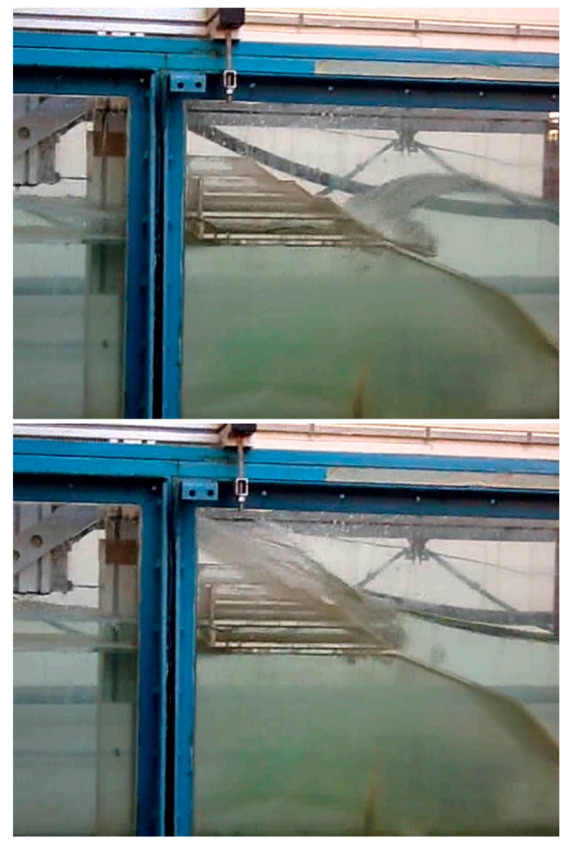

(a)

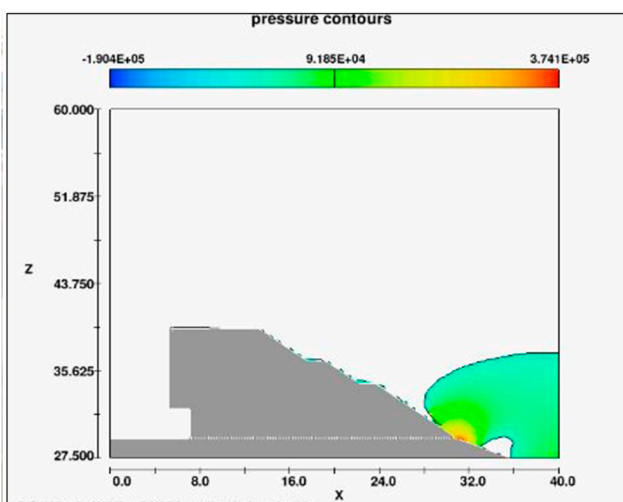

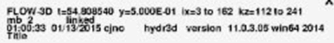

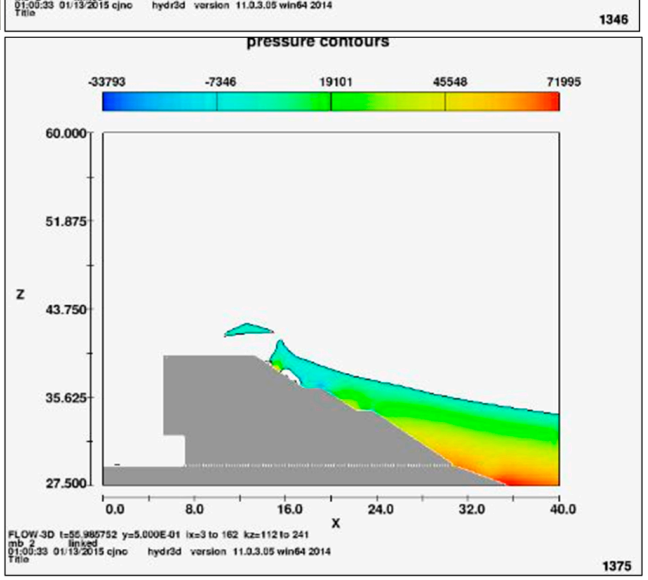

(b)

Figure 16. Wave shape at the wall for test B: (a) physical experiment; and (b) CFD numerical simulation.

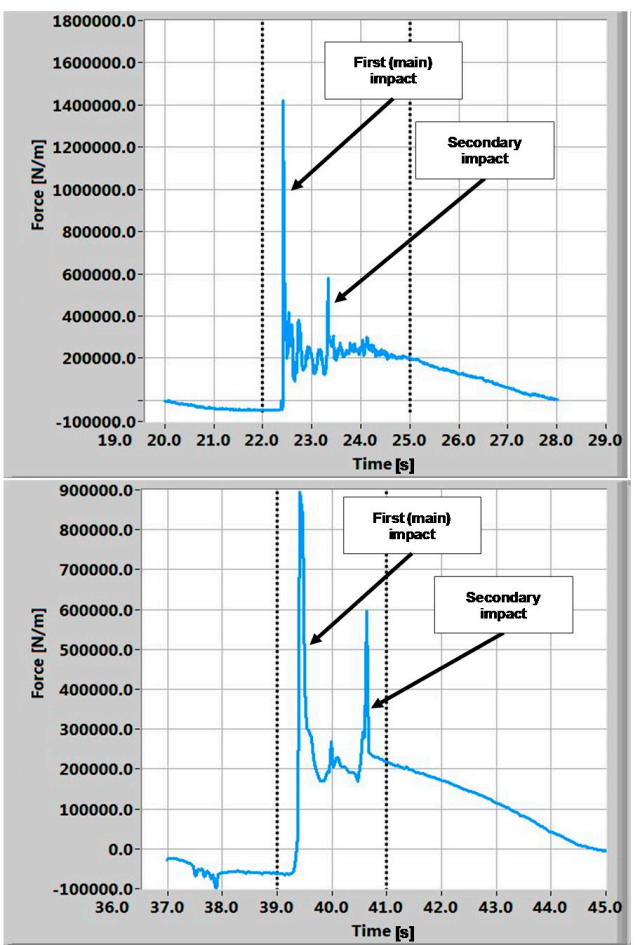

(a)

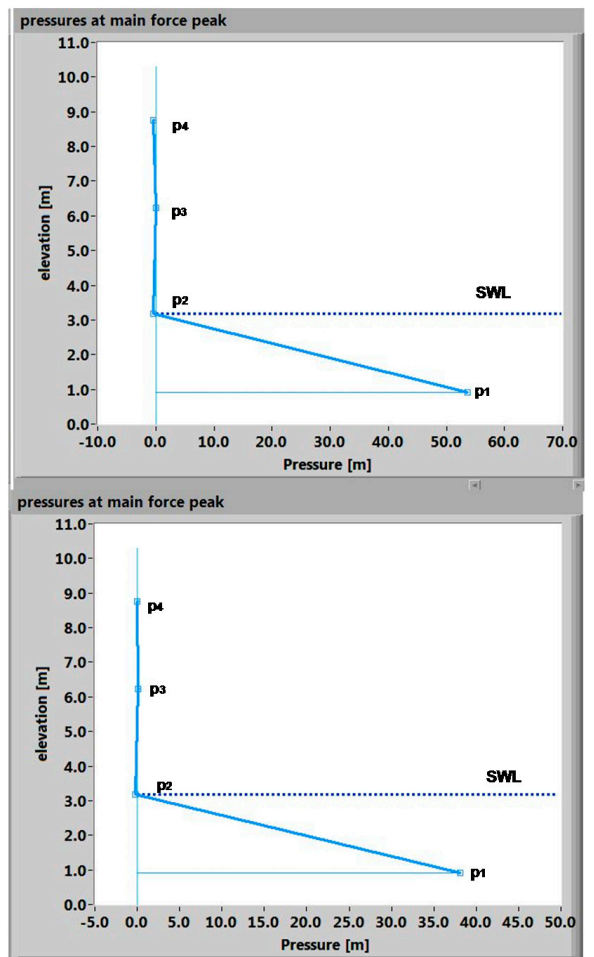

(b)

Figure 17. (a) Time history of horizontal force for physical (upper panel) and CFD (lower panel); and (b) pressure distribution at the peak (pressures are in water column). 


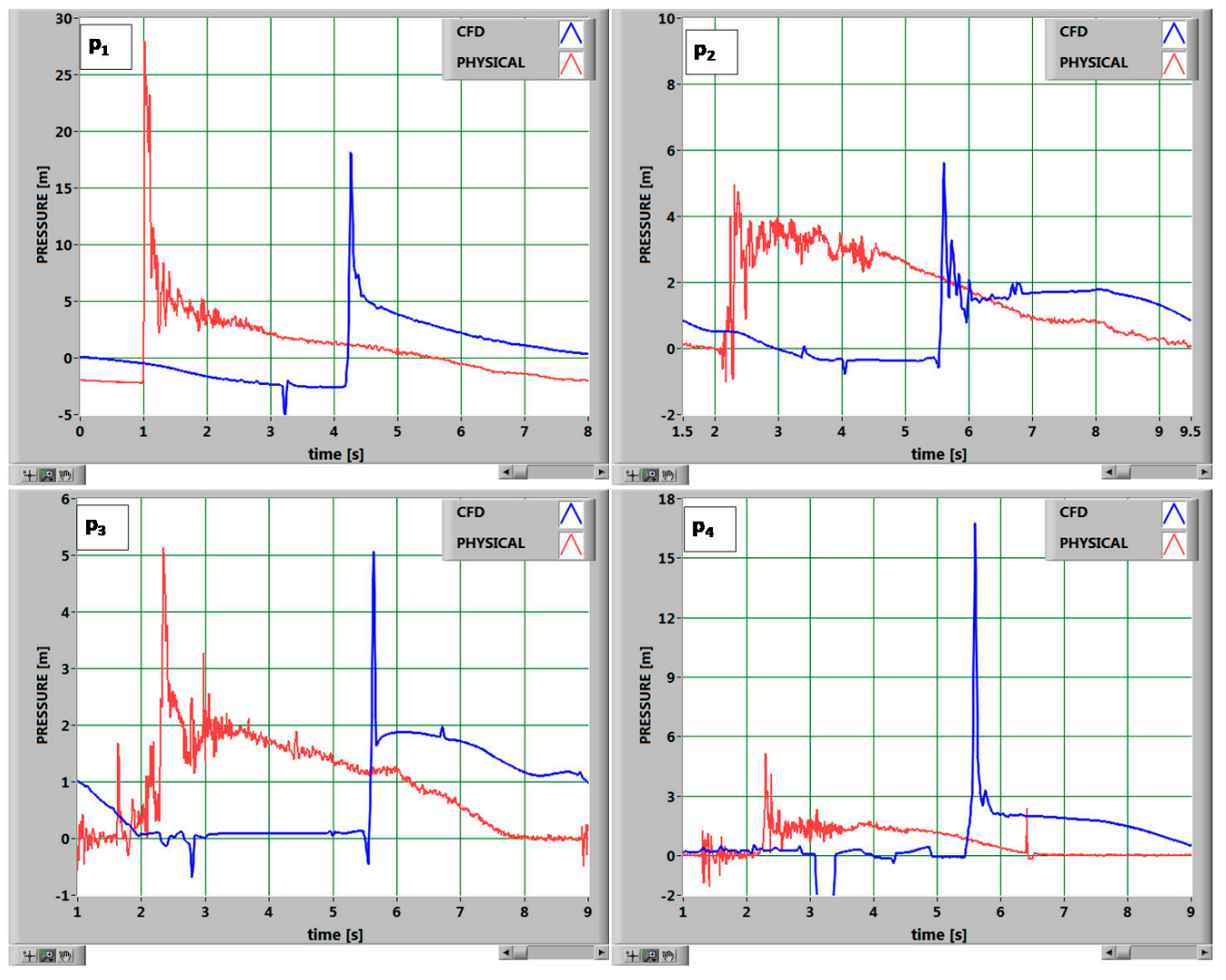

Figure 18. Pressure chronograms for test 12. Pressures are expressed in water column. $\mathrm{p}_{1}$ : pressure transducer at the toe of the structure; $\mathrm{p}_{2}$ at the still water level; $\mathrm{p}_{3}$ and $\mathrm{p}_{4}$ on the upper plates (see Figure 10).

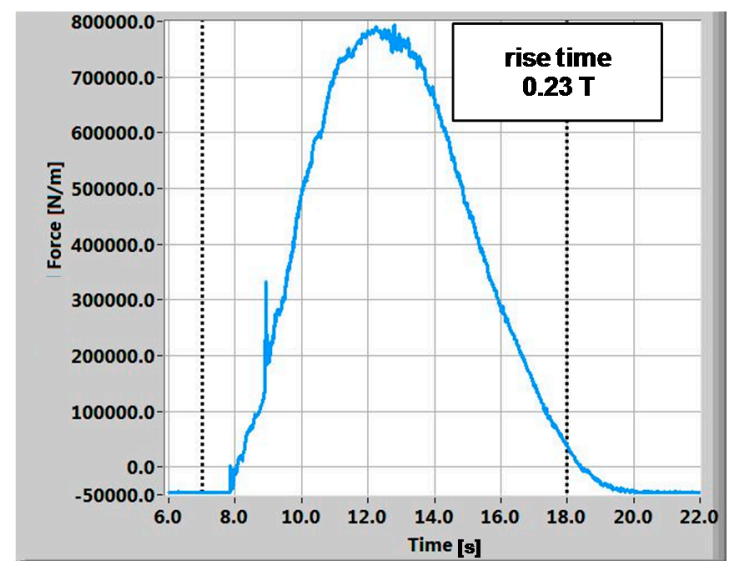

(a)

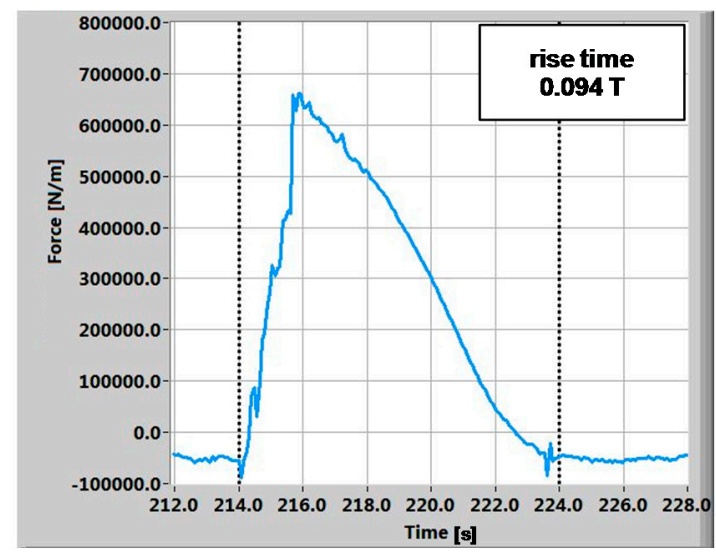

(b)

Figure 19. Pulsating loading case for test C: (a) physical model test; and (b) CFD simulation. 


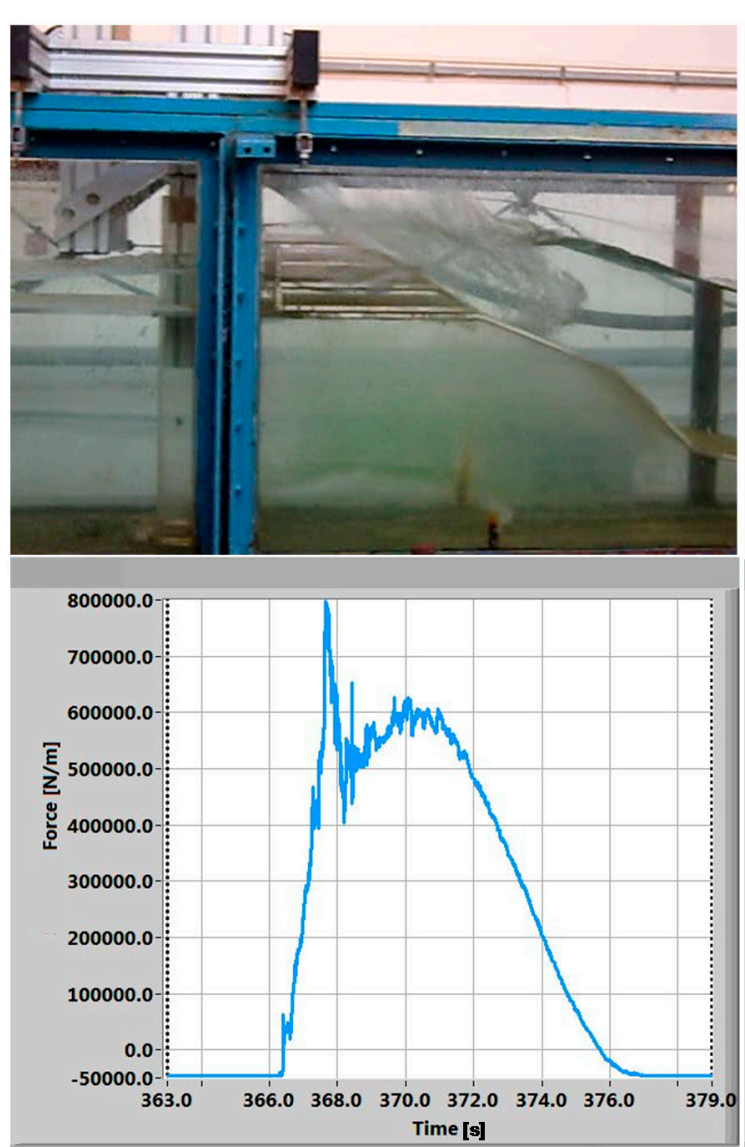

(a)

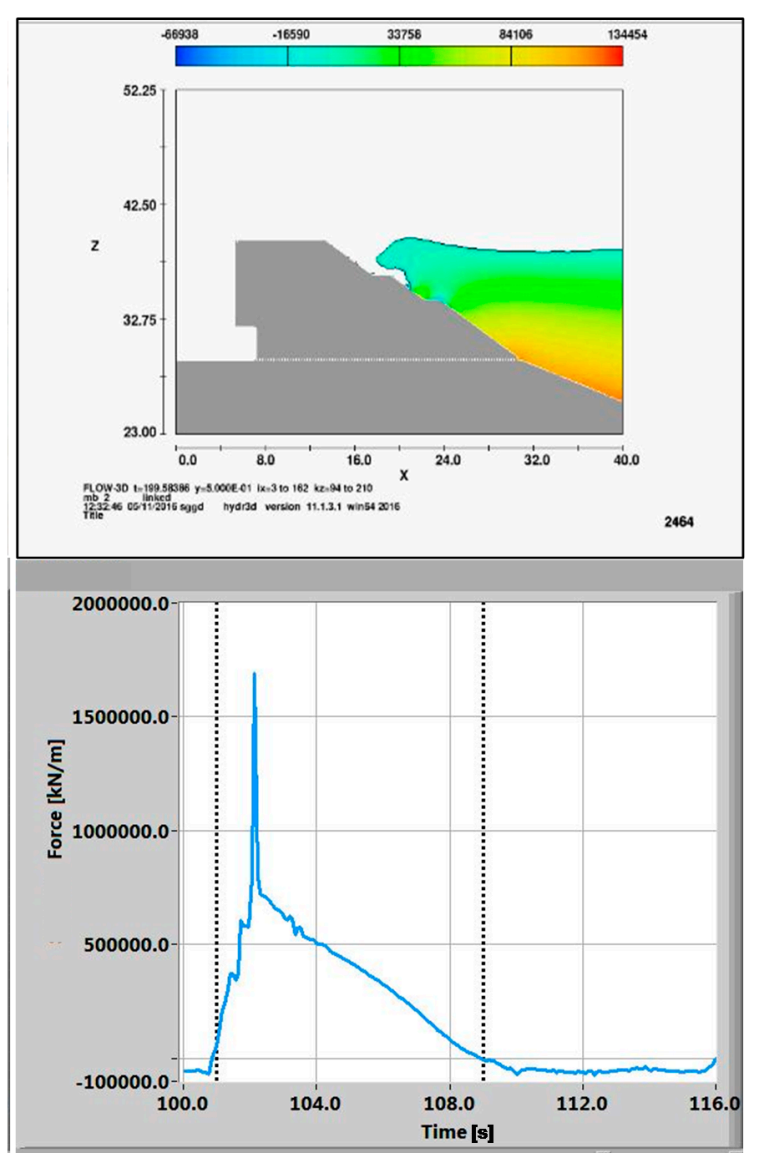

(b)

Figure 20. Example of water tongue slamming during the up-rush phase (test C): (a) physical model test; and (b) CFD simulations.

\subsection{Wave Loadings Magnitude and Distribution}

In addition, for the numerical simulations, the peaks of the non-dimensional average pressure $\hat{p}_{a v} / \rho g d$ resulted approximately log-normal distributed; an example is shown in Figure 21.

Moreover, the mean of the probability density functions ( $p d f s$ ) has been found to attain values rather consistent with the physical model tests, both in the case of impulsive and non-impulsive wave actions. Figures 22 and 23 show that the CFD data lay rather close to the Buccino et al. experiments [15], but for a single plunging breaker circled in Figure 23.

As a further point of interest, it is noteworthy that for non-impact loadings, the gathering of numerical and physical points would seem to support the hypothesis (already formulated in Buccino et al. [15]) that the relationship between the average pressure and $L_{T P}$ may actually be weakly nonlinear. The following slight correction to the Equation (6) can be then proposed (Figure 21, broken line):

$$
E\left(\hat{p}_{a v} / \rho g d=0.7 L_{T P^{0.93}}\right.
$$

with a $R^{2}$ statistics of 0.98 . 

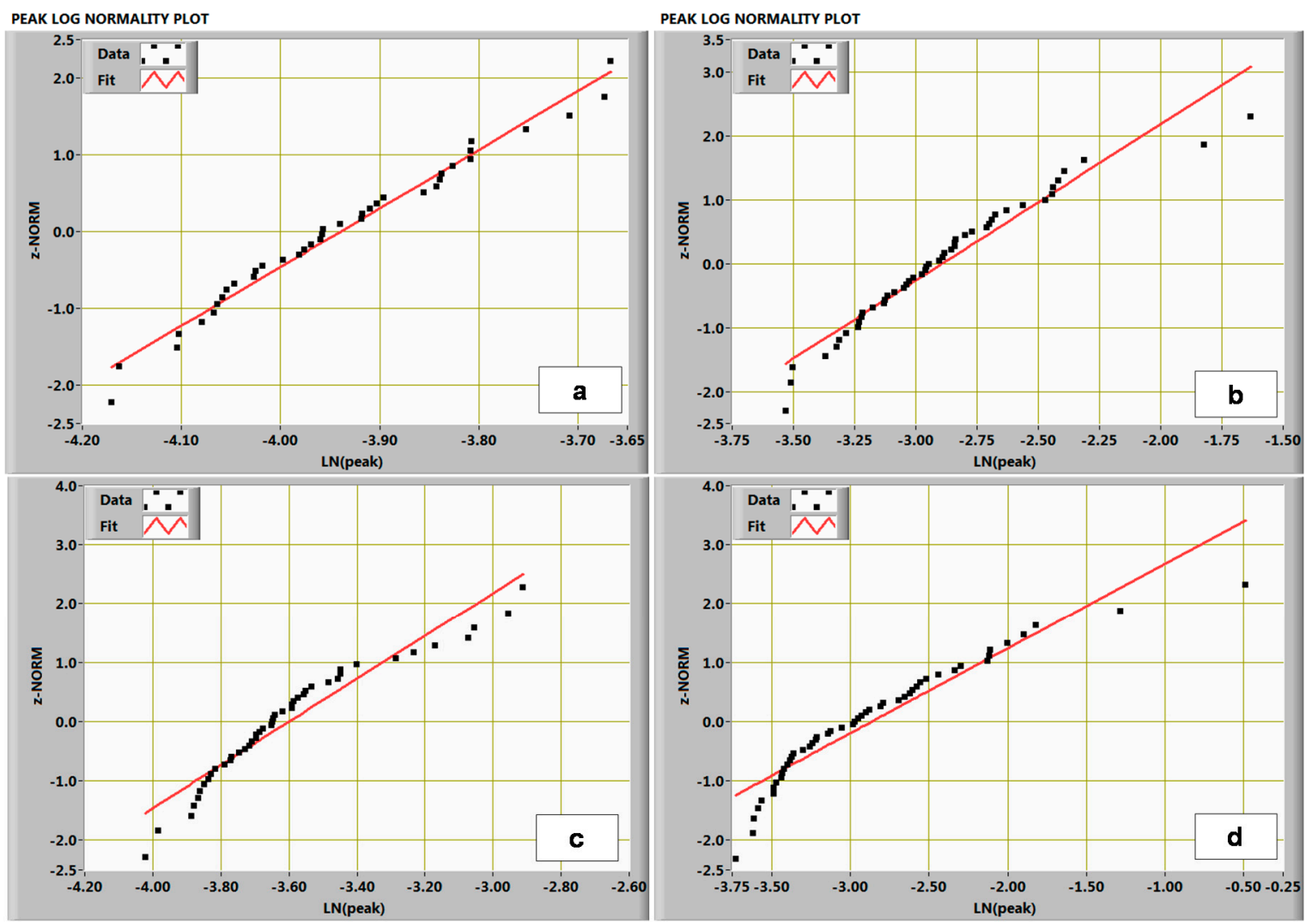

Figure 21. Log-Normal plots of the force peaks for CFD simulations: (a) Test 6; (b) Test 12; (c) Test 7; and (d) Test 17.

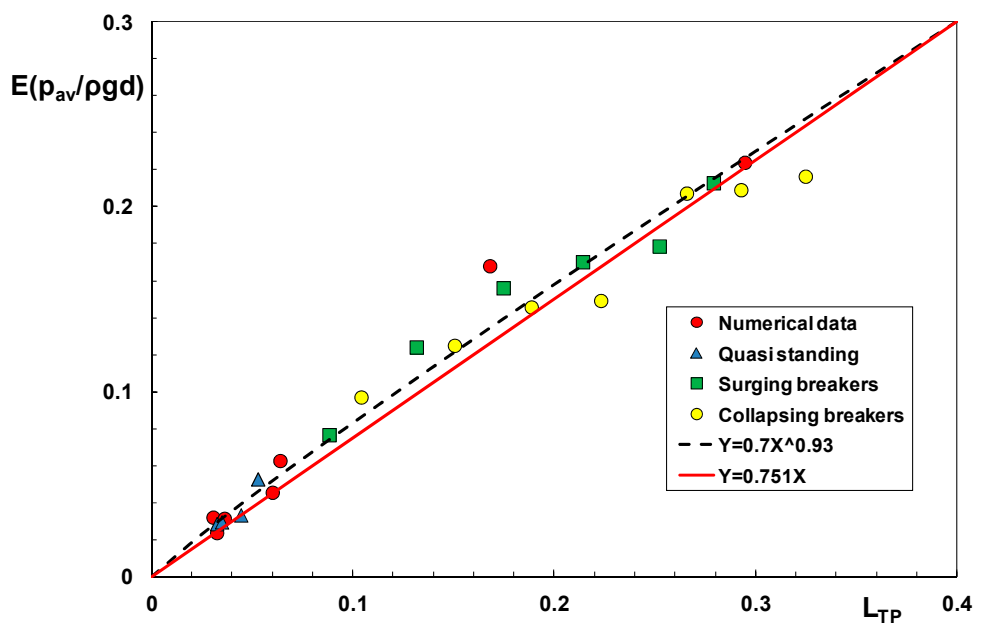

Figure 22. Expected non-dimensional mean pressure ( $\left.\hat{p}_{a v} / \rho g d\right)$ vs. $L_{T P}$ (non-impact waves).

As far as the standard deviation is concerned, the variables $t$ and $u$ resulted poorly correlated to the scatter of the numerical $p d f s$; in general, the CFD distribution would seem to have a variance far larger than that predicted by the Equation (7) (Figures 24 and 25). 


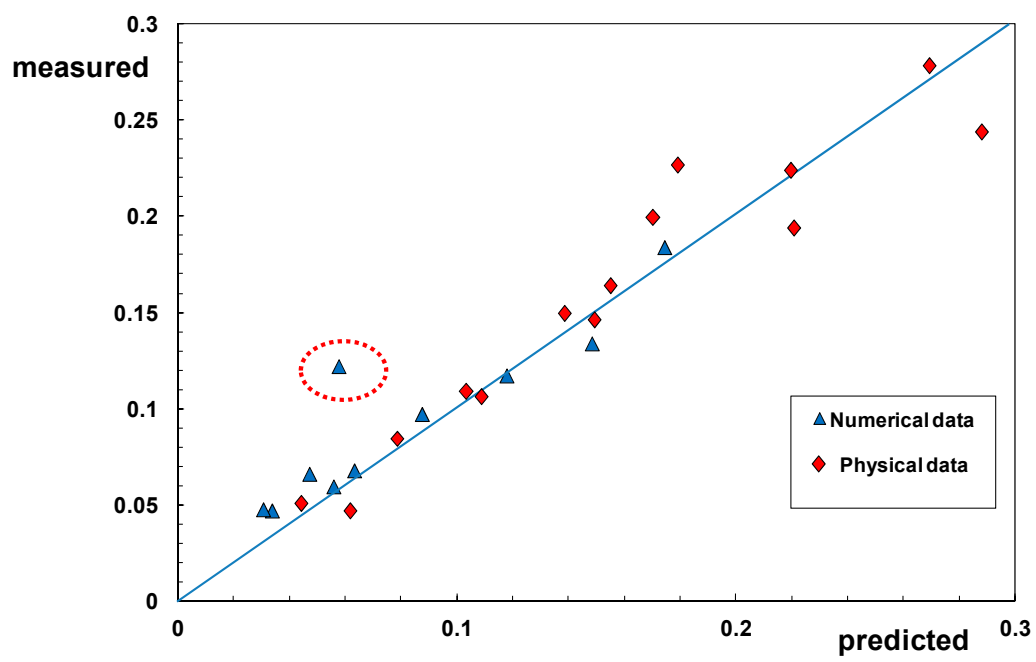

Figure 23. Measured vs. predicted $\hat{p}_{a v} / \rho g d$ for impact waves. The unique observed outlier is red-circled in the graph.

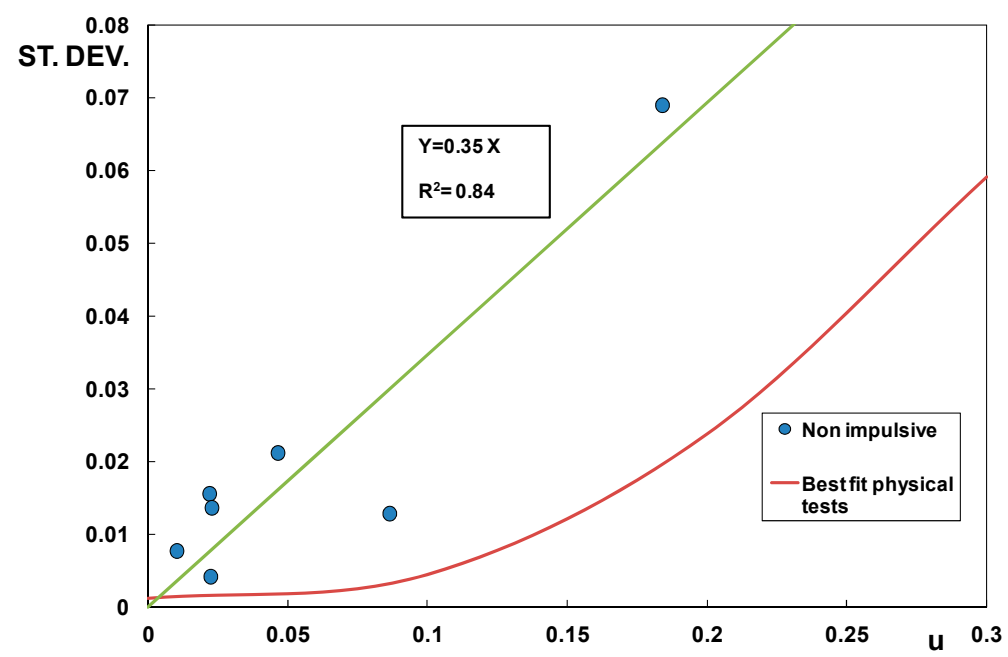

Figure 24. Standard deviation of $\hat{p}_{a v} / \rho g d$ vs. the variable $u$ of Equation (8). Non-impact waves.

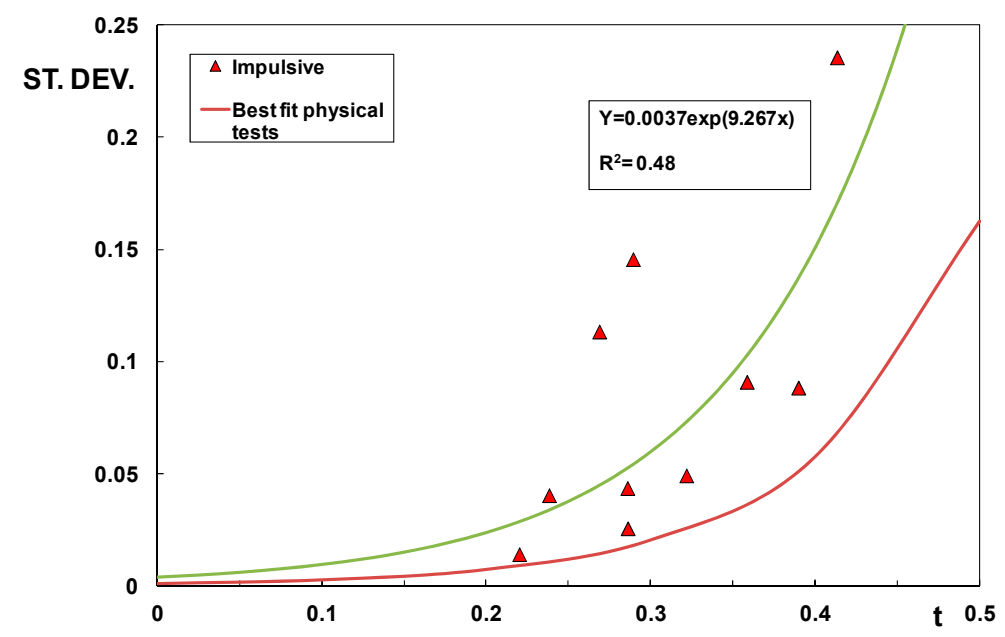

Figure 25. Standard deviation of $\hat{p}_{a v} / \rho g d$ vs. the variable $t$ of Equation (8). Impact waves. 
However, as shown in Figure 26, when physical and numerical data are plotted against the Iribarren number alone, a reasonable accordance is observed, with the exception of a single outlier circled in red in the graph. The trend of points can be represented by the following power type relationship:

$$
\sqrt{\operatorname{VAR}\left(\frac{\hat{p}_{a v .}}{\rho g d}\right)}=0.0108(\xi-1)^{-1.263}
$$

which is suggested to be used as new design formula instead of Equation (7). As a point of strength, the new tool holds for both impact and non-impact conditions; on the other hand, it has to be pointed out that the determination index is some low $\left(R^{2}=0.61\right)$ and the lack of dependence on the linear thrust parameter may lead to largely overestimate the variance of steep standing waves, which have low $\xi$ and low $L_{T P}$. From an engineering point of view, however, the latter appears conservative, as it leads to overestimate the maximum predicted force for assigned $H_{i}$ and $T$.

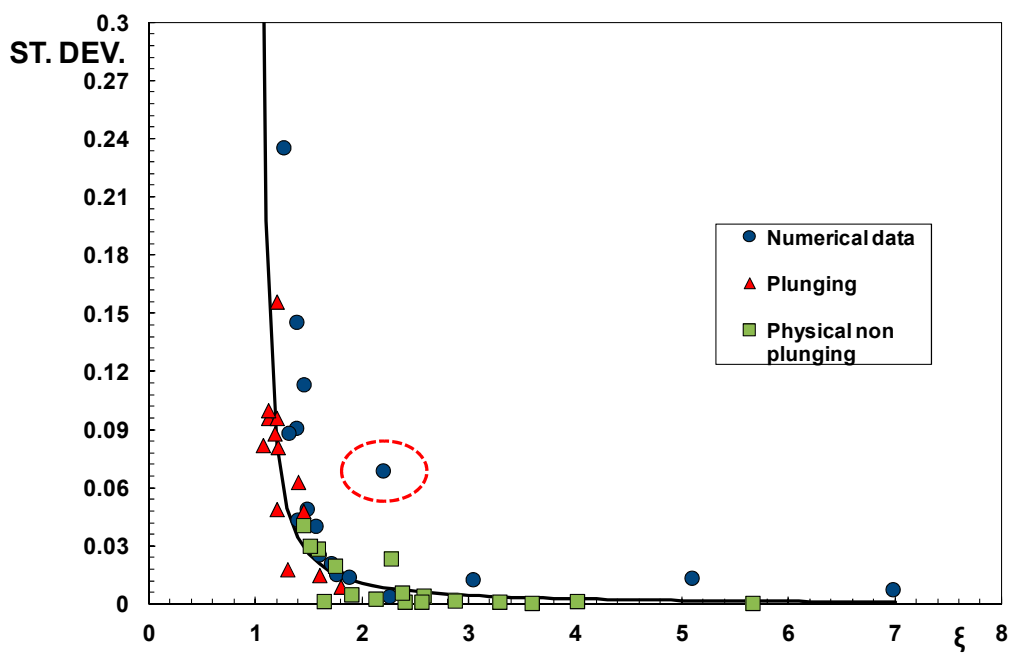

Figure 26. Standard deviation of $\hat{p}_{a v} / \rho g d$ vs. $\xi$. The unique observed outlier is red-circled in the graph.

\section{Conclusions}

The capability of CFD simulations of reproducing the main qualitative and quantitative features of wave loadings acting onto the front face of Seawave Slot-cone Generators has been investigated through 17 numerical experiments conducted via the suite Flow 3D. The WEC modeled, and the foreshore in front of it, are geometrically identical to those employed by [15] in the frame of a physical model study conducted at the LInC laboratory of the University of Napoli "Federico II". Numerical and physical model data resulted generally consistent with each other; the main differences found concern:

- The presence of undesired spikes in the numerical force chronogram of a standing wave, due to small local impacts provoked by the run-up wedge during the up-rush phase (Figures 13 and 14).

- A weak tendency of CFD at progressively increasing in time the phase difference relative to the physical model (Figure 15 upper panels).

- The presence in the numerical tests of impact events generated by large surging breakers (Figure 19), due to the not modeling of the air that dampens the force peaks in the physical experiments.

However, the magnitude and the statistical properties of the numerically simulated wave loadings were found to be fairly in agreement with the physical model measurements. The observed consistency allowed modifying the predictive Equations (6) and (7), in order to account for the new results (Equations (11) and (12)). 
On the whole, this study supports the idea that CFD could be effectively employed in the structural design of SSGs, even if the consequences of the inclusion of air within the fluid mass should be accurately investigated. Moreover, supplementary studies are needed to compare numerical and physical model outcomes in the case of random waves.

Finally, the reliability of alternative meshless advanced numerical methods, such as Smooth Particle Hydrodynamics (SPH), deserve being investigated in depth.

Author Contributions: All the authors contributed to the analysis and discussion of results.

Conflicts of Interest: The authors declare no conflict of interest.

\section{References}

1. Frankfurt School FS-UNEP Collaborating Centre for Climate and Sustainable Energy Finance. Global Trend in Renewable Energy Investment; FS-UNEP Publishing: Frankfurt, Germany, 2016.

2. Clement, A.; McCullen, P.; Falcao, A.; Fiorentino, A.; Gardner, F.; Hammarlund, K.; Lemonis, G.; Lewis, T.; Nielsen, K.; Petroncini, S.; et al. Wave energy in Europe: Current status and perspectives. Renew. Sustain. Energy Rev. 2002, 6, 405-431. [CrossRef]

3. Azzellino, A.; Conley, D.; Vicinanza, D.; Kofoed, J.P. WECs will likely become diffuse in the near future, thus impacting the further transformation of coastal zones. Marine Renewable Energies: Perspectives and Implications for Marine Ecosystems. Sci. World J. 2013, 2013, 85-88.

4. Falnes, J. (Ed.) Ocean Wave Energy; Cambridge University Press: Cambridge, UK, 2002.

5. Buccino, M.; Vicinanza, D.; Stagonas, D.; Muller, G. Development of a composite seawall wave energy conversion system. Renew. Energy 2015, 81, 509-522. [CrossRef]

6. Zhang, X.T.; Yang, J.M.; Xiao, L.F. An oscillating wave energy converter with nonlinear snap-through Power-Take-Off systems in waves regular. Chin. Ocean Eng. 2016, 30, 565-580. [CrossRef]

7. Zhang, X.T.; Yang, J.M. Power capture performance of an oscillating-body WEC with nonlinear snap through PTO systems in irregular waves. Appl. Ocean Res. 2016, 52, 261-273. [CrossRef]

8. Kofoed, J.P.; Bingham, H.; Christensen, E.D.; Zanuttigh, B.; Martinelli, L.; Castagnetti, M.; Bard, J.; Kracht, P.; Frigaard, P.; Nielsen, K.; et al. State of the Art Descriptions and Tasks for Structural Design of Wave Energy Devices; Department of Civil Engineering, Aalborg University: Aalborg, Denmark, 2010.

9. GEOwave Consortium. Available online: http//www.geowave-r4sme.eu (accessed on 1 September 2016).

10. Vicinanza, D.; Contestabile, P.; Harck Nørgaard, J.Q.; Lykke Andersen, T. Innovative rubble mound breakwaters for overtopping wave energy conversion. Coast. Eng. 2014, 88, 154-170. [CrossRef]

11. Elhanafi, A. Prediction of regular wave loads on a fixed offshore oscillating water column-wave energy converter using CFD. J. Ocean Eng. Sci. 2016. [CrossRef]

12. Margheritini, L.; Vicinanza, D.; Frigaard, P. SSG wave energy converter: Design, reliability and hydraulic performance of an innovative overtopping device. J. Renew. Energy 2009, 34, 1371-1380. [CrossRef]

13. Vicinanza, D.; Margheritini, L.; Kofoed, J.P.; Buccino, M. The SSG wave energy converter: Performance, status and recent developments. Energies 2012, 5, 193-226. [CrossRef]

14. Buccino, M.; Banfi, D.; Vicinanza, D.; Calabrese, M.D.; Giudice, G.; Carravetta, A. Non breaking wave forces at the front face of Seawave Slotcone Generators. Energies 2012, 5, 4779-4803. [CrossRef]

15. Buccino, M.; Vicinanza, D.; Salerno, D.; Banfi, D.; Calabrese, M. Nature and magnitude of wave loadings at Seawave Slot-cone Generators. Ocean Eng. 2015, 95, 34-58. [CrossRef]

16. Vicinanza, D.; Frigaard, P. Wave pressure acting on a seawave slot-cone generator. Coast. Eng. 2009, 55, 553-568. [CrossRef]

17. Takahashi, S.; Hosoyamada, S.; Yamamoto, S. Hydrodynamic characteristics of sloping top caissons. In Proceedings of the International Conference on HydroTechnical Engineering for Port and Harbor Construction, 1. Port and Harbour, Yokosuka, Japan, 19-21 October 1994; Port and Harbour Research Institute: Tokyo, Japan, 1994; pp. 733-746.

18. Vicinanza, D.; Ciardulli, F.; Buccino, M.; Calabrese, M.; Kofoed, J.P. Wave loadings acting on an innovative breakwater for energy production. J. Coast. Res. 2011, 64, 608-612.

19. Tanimoto, K.; Kimura, K. A hydraulic Experiment Study on Trapezoidal Caisson Breakwaters; Port and Harbour Research Institute: Yokosuka, Japan, 1985. 
20. Battjes, J.A. Surf similarity. In Proceedings of the 14th Coastal Engineering Conference, Copenhagen, Denmark, 24-28 June 1974.

21. Svendsen, I.B.A. Introduction to Nearshore Hydrodynamics; World Scientific: Singapore, 2006.

22. Hughes, S.A. Wave momentum flux parameter: A descriptor for nearshore waves. Coast. Eng. 2004, 51, 1067-1084. [CrossRef]

23. Calabrese, M.; Vicinanza, D.; Buccino, M. 2D wave setup behind low crested and submerged breakwaters. In Proceedings of the 13th International Offshore and Polar Engineering Conference, Honolulu, HI, USA, 25-30 May 2003.

24. Calabrese, M.; Buccino, M.; Pasanisi, M. Wave breaking macrofeatures on a submerged rubble mound break water. J. Hydro-Environ. Res. 2008, 1, 216-225. [CrossRef]

25. Oumeraci, H.; Allsop, N.W.H.; De Groot, M.B.; Crouch, R.S.; Vrijling, J.K. Probabilistic Design Tools for Vertical Breakwaters; Balkema: Rotterdam, The Netherlands, 1999.

26. Peregrine, D.H. Water wave impact on walls. Ann. Rev. Fluid Mech. 2003, 35, 23-44. [CrossRef]

27. Calabrese, M.; Buccino, M. Wave Impacts on vertical and composite breakwaters. In Proceedings of the 10th International Offshore and Polar Engineering Conference, Seattle, WA, USA, 28 May-2 June 2000.

28. Flow Science Inc. Suite Flow 3D; Flow Science Inc.: Santa Fe, Mexico, 2009.

29. Dentale, F.; Donnarumma, G.; Pugliese Carratelli, E. Simulation of flow within armour blocks in a breakwater. J. Coast. Res. 2014, 30, 528-536. [CrossRef]

30. Dentale, F.; Donnarumma, G.; Pugliese Carratelli, E. Numerical wave interaction with Tetrapods breakwater. J. Naval Arch. Ocean Eng. 2014, 6, 800-812. [CrossRef]

31. Kortenhaus, A.; van der Meer, J.W.; Burcharth, H.F.; Geeraerts, J.; van Gent, M.; Pullen, T. Final Report on Scale Effects; CLASH WP7-Report; LWI: Braunschweig, Germany, 2004.

32. Zanuttigh, B.; Margheritini, L.; Gambles, L.; Martinelli, L. Analysis of wave reflection from Wave Energy Converters installed as breakwaters in harbors. In Proceedings of the European Wave and Tidal Energy Conference (EWTEC), Uppsala, Sweden, 7-10 September 2009.

33. Zelt, J.A.; Skjelbreia, J.E. Estimating incident and reflected wave field using an arbitrary number of wave gauges. In Proceedings of the International Conference on Coastal Engineering, Venice, Italy, 4-9 October 1992; pp. 777-789.

34. Basco, D. A qualitative description of wave breaking. J. Waterw. Port Coast. Ocean Eng. 1985, 111, $171-188$. [CrossRef]

35. Goda, Y. Random Seas and Design of Maritime Structures; World Scientific: Singapore, 2010. 